J. Appl. Glycosci., 57, 245-264 (2010)

(C) 2010 The Japanese Society of Applied Glycoscience

Regular Paper

\title{
Proteomic Analysis of Theobroma cacao Pod Husk
}

(Received June 24, 2010; Accepted July 14, 2010)

\author{
Azwan Awang, ${ }^{1,2, *}$ Rafiah Karim ${ }^{2}$ and Toshiaki Mitsui ${ }^{1, *}$ \\ ${ }^{1}$ Laboratories of Plant and Microbial Genome Control, Graduate School of Science \\ and Technology, Niigata University (2-Ikarashi, Nishi-ku, Niigata 950-2181, Japan) \\ ${ }^{2}$ Malaysian Cocoa Board, Locked Bag 211 \\ (88999 Kota Kinabalu, Sabah, Malaysia)
}

\begin{abstract}
We performed two dimensional electrophoresis (2-DE) coupled with MS analysis on Theobroma cacao pod husk (fruit pericarp) to explore the proteome of this recalcitrant tissue. Using a phenol extraction/ methanol-ammonium acetate precipitation method, we have obtained 2-DE images with approximately 700 protein spots detected after colloidal CBB staining. Two hundred and forty-four protein spots were analyzed by de novo sequencing of SPITC-derivatized tryptic peptides by MALDI-TOF/TOF MS. Applying this technique, 144 protein spots from cocoa pod husk were identified. The majority of the identified proteins were involved in metabolism and energy. Several of these proteins could be linked to pod growth and development processes.
\end{abstract}

Key words: Theobroma cacao, pod husk, 2-DE, MALDI-TOF/TOF MS, de novo sequencing

Cocoa (Theobroma cacao L.) is an important crop for many tropical countries and is mainly cultivated for its beans (seeds) for making chocolate. In Malaysia and other Southeast Asian countries, cocoa production is plagued by the cocoa pod borer (CPB) moth, Conopomorpha cramerella Snellen. ${ }^{1)}$ Damage is caused by larvae that bore into the pod and feed on the placenta and pulp tissue surrounding the beans. This disrupts nutrient and water flow to developing beans and results in premature pod ripening. ${ }^{2)}$ The resulting immature beans clump together and become unextractable, and are low in cocoa butter (triacylglycerol) quality. ${ }^{3-5)}$ Current control efforts rely heavily on the use of insecticides, which are expensive and dangerous. ${ }^{6}$ )

In the search for host plant resistance, many studies have been focused on the relationship of pod morphology and anatomy to CPB infestation. ${ }^{1,3,7)}$ It was found that the hardness and thickness of the sclerotic layer plays an important role in CPB resistance. ${ }^{3)}$ The sclerotic layer is a lignified layer of tissue in the middle of the pod husk. The harder and thicker the sclerotic layer, the more difficult it is for CPB larvae to penetrate into or out of the pod. Other non-physical elements may also contribute to CPB resistance, but no studies have yet been conducted. Nevertheless, there is still very little knowledge on many aspects of pod development, particularly at the cellular

\footnotetext{
* Corresponding authors (Tel. \& Fax. +81-25-262-6641, E-mail: azwan@koko.gov.my (Azwan Awang), t.mitsui@agr.niigata-u.ac. jp (T. Mitsui)).

Abbreviations: CPB, cocoa pod borer; 2-DE, 2-dimensional electrophoresis; MALDI-TOF/TOF MS, matrix-assisted laser desorption ionization-time of flight/time of flight mass spectrometer; SPITC, 4-sulfophenyl isothiocyanate; PSD, post source decay; ACN, acetonitrile; HCCA, $\alpha$-cyanohydroxycinnamic acid; TFA, trifluoroacetic acid; DTT, dithiothreitol; IAA, iodoacetamide; $\mathrm{BPB}$, bromophenol blue; CBB, Coomassie Brilliant Blue; IEF, isoelectric focusing.
}

and molecular level.

Proteomics offers an alternative and powerful method to address biological problems that cannot be dealt with adequately by genomics. ${ }^{9)}$ It has been used extensively in many plants including important crops. ${ }^{10,11)}$ Currently a gel-based approach using 2-DE coupled with MS is still widely used as the core technique in proteomics. ${ }^{12,13)} 2-\mathrm{DE}$ gives high resolution of intact proteins from large complex protein mixtures that reveal changes in isoforms, post-translational modifications, and protein expression levels, and at a reasonable cost. ${ }^{13,14)}$ Furthermore, it is recommended as an excellent proteomic approach for nonmodel plants, ${ }^{15)}$ such as cocoa.

To date, only a few proteomic analyses have been reported for cocoa. Previous studies were done to investigate protein changes in beans during fruit ripening, fermentation and other processes in chocolate making. ${ }^{16,17)}$ Recently, protein extraction for 2-DE has been established for leaves and meristem. ${ }^{18)}$ There is no proteomic study, however, for pod husk, and none for any cocoa tissue combining 2-DE with MS. Pod husk is especially rich in polyphenols (particularly procyanidins) and gums (charged polysaccharides). ${ }^{19-21)}$ Such compounds can hamper protein isolation, 2-DE analysis, and protein identification by MS. ${ }^{14,22)}$ Thus, a suitable sample preparation for pod husk is needed.

Here, we report on the extraction of total proteins from cocoa pod husk for 2-DE analysis and also identification of the major proteins by MALDI-TOF/TOF MS to analyzing the pod husk proteome. For protein identification, we used de novo sequence analysis and cross species homology search, because the complete cocoa genome is not yet available. Sequencing was aided by simplified MALDI-TOF/TOF MS spectra obtained by $N$-terminal sulfonation of tryptic peptides. The same technique has also been used in other unsequenced organisms. ${ }^{23-26)}$ To the best of our knowledge, this is the first extensive report 
on proteomics of any tissue in cocoa.

\section{MATERIALS AND METHODS}

Plant materials. Three-month-old healthy pods from two clones, LAFI7 and ICS39, were obtained by hand pollination from Sabah Department of Agriculture, Quoin Hill Agriculture Research Station, Tawau, Sabah, Malaysia.

Preparation of acetone dried powder (AcDP). AcDP was prepared according to the method described by Wang et $a$. $^{22)}$ with modification. Beans and placenta were removed from the pod and the remaining pod husk was cut into small pieces, immediately frozen in liquid nitrogen, and lyophilized. Lyophilized pod husk (0.2 g) was wrapped with aluminum foil and crushed with pestle and mortar under liquid nitrogen. The resulting powder was additionally ground directly in liquid nitrogen into a fine powder. The pod husk powder was then resuspended in $10 \mathrm{~mL}$ of ice-cold acetone and vortexed for $5 \mathrm{~min}$. After centrifugation $\left(10,000 \times g, 5 \mathrm{~min}, 4^{\circ} \mathrm{C}\right)$, the supernatant was discarded. This step was performed three times and the resulting polyphenol-free white powder was air-dried.

Protein extraction. Protein extraction was performed according to the method described by Carpentier et al. ${ }^{14)}$ with minor modification. AcDP $(0.2 \mathrm{~g})$ was ground further for $5 \mathrm{~min}$ before resuspending in $10 \mathrm{~mL}$ ice-cold extraction buffer (50 mM Tris- $\mathrm{HCl} \mathrm{pH} 8.5,5 \mathrm{~mm}$ EDTA, $100 \mathrm{~mm} \mathrm{KCl}, 2 \% \beta$-mercaptoethanol, 30\% sucrose) inside a pre-chilled mortar and mixed thoroughly with a pestle. To the highly viscous homogenate (due to gum), $10 \mathrm{~mL}$ ice-cold Tris buffered phenol (reagent-grade phenol equilibrated with $50 \mathrm{~mm}$ Tris-HCl, $\mathrm{pH} 8.0$ ) was added and the homogenate mixed further for $5 \mathrm{~min}$. The homogenate was then transferred to a $50 \mathrm{~mL}$ Falcon tube, vortexed for $15 \mathrm{~min}$, and centrifuged $\left(10,000 \times g, 10 \mathrm{~min}, 4^{\circ} \mathrm{C}\right)$. The top phenolic phase was re-extracted with $10 \mathrm{~mL}$ extraction buffer. After centrifugation $(10,000 \times g, 10 \mathrm{~min}, 4$ $\left.{ }^{\circ} \mathrm{C}\right)$, the phenolic phase was collected and 5 volumes of $100 \mathrm{~mm}$ ammonium acetate in methanol was added. The mixture was then incubated overnight at $-20^{\circ} \mathrm{C}$ to precipitate protein. Protein was pelleted by centrifugation $\left(10,000 \times g, 20 \mathrm{~min}, 4^{\circ} \mathrm{C}\right)$ and rinsed twice in ice-cold acetone $/ 0.2 \%$ DTT with $60 \mathrm{~min}$ incubation at $-20^{\circ} \mathrm{C}$ between the two rinsing steps. After air-drying, the protein pellet was resolubilized in $400 \mu \mathrm{L}$ resolubilization buffer (7 $\mathrm{M}$ urea, $2 \mathrm{M}$ thiourea, 4\% CHAPS, 0.5\% IPG-buffer pH 3-10, 20 mM DTT). Finally, the suspension was centrifuged $\left(10,000 \times g, 3 \mathrm{~min}, 20^{\circ} \mathrm{C}\right)$ and the supernatant was collected for 2-DE application. Protein concentration was determined using a 2-D Quant Kit (GE Healthcare, Hercules, UK).

2-DE. A three-hundred-microgram $(300 \mu \mathrm{g})$ protein sample in $450 \mu \mathrm{L}$ rehydration solution (resolubilization buffer with trace of BPB) was applied to a $24 \mathrm{~cm} \mathrm{pH} \mathrm{4-7}$ linear IPG strip (GE Healthcare) and rehydrated for $12 \mathrm{~h}$. IEF was performed on the Ettan IPGphor II system (GE Healthcare) at $20^{\circ} \mathrm{C}$ with the following settings: current limit, $50 \mu \mathrm{A} /$ strip; $200 \mathrm{~V}, 15 \mathrm{~min} ; 500 \mathrm{~V}, 15 \mathrm{~min} ; 1 \mathrm{kV}$, $30 \mathrm{~min} ; 8 \mathrm{kV}, 1 \mathrm{~h}$ (gradient); $8 \mathrm{kV}, 54325 \mathrm{Vh}$. Focused strips were then equilibrated twice in $10 \mathrm{~mL}$ equilibration solution (6 M urea, 30\% glycerol, $2 \%$ SDS, $0.002 \%$ BPB, $50 \mathrm{mM}$ Tris $\mathrm{pH} 8.8$ ) for $15 \mathrm{~min}$. The first equilibration solution contained 1\% DTT and the 2nd contained $2.5 \%$ IAA. SDS-PAGE was performed on the Ettan DALT 6 System (GE Healthcare) by using lab-cast $1 \mathrm{~mm}$ SDS polyacrylamide gels $(12.5 \%)$ with the following settings: $10 \mathrm{~mA} / \mathrm{gel}, 1 \mathrm{~h} ; 38 \mathrm{~mA} / \mathrm{gel}$, until the BPB line reached the bottom of the glass. Proteins were visualized by colloidal CBB staining. ${ }^{27}$ Gels were scanned with a PharosFX Molecular Imager System (Bio-Rad Laboratories, Inc., Hercules, USA) and image analysis was performed using PDQuest 8.0.1 (Bio-Rad Laboratories, Inc.).

In-gel digestion. Protein spots were excised from colloidal CBB-stained-2-DE gels and washed with $50 \mathrm{~mm}$ $\mathrm{NH}_{4} \mathrm{HCO}_{3}$, followed by destaining with $50 \% \mathrm{ACN}$ in 50 $\mathrm{mM} \mathrm{NH}_{4} \mathrm{HCO}_{3}$. The gels were dehydrated by $\mathrm{ACN}$ and dried completely in a speed vacuum. The proteins were reduced by incubation in $50 \mu \mathrm{L} 10 \mathrm{mM}$ DTT in $50 \mathrm{~mm}$ $\mathrm{NH}_{4} \mathrm{HCO}_{3}$ for $45 \mathrm{~min}$ at $56^{\circ} \mathrm{C}$ and subsequently alkylated by incubation in $55 \mathrm{~mm}$ IAA in $50 \mathrm{mM} \mathrm{NH}_{4} \mathrm{HCO}_{3}$ for 45 min at $30^{\circ} \mathrm{C}$ in darkness. The gels were washed twice with $50 \mathrm{mM} \mathrm{NH} \mathrm{NCO}_{3}$ and twice with $50 \% \mathrm{ACN}$ in 50 $\mathrm{mM} \mathrm{NH}_{4} \mathrm{HCO}_{3}$. The gels were dehydrated again as described above. Dried gels were re-swelled by incubation in $10 \mu \mathrm{L}$ trypsin solution $(10 \mathrm{ng} / \mu \mathrm{L}$ sequencing-grade modified porcine trypsin (Promega Corporation, Madison, USA) in $50 \mathrm{~mm} \mathrm{NH}_{4} \mathrm{HCO}_{3} \mathrm{pH}$ 7.8) for $45 \mathrm{~min}$ on ice. Excess trypsin solution was removed and gels were incubated at $37^{\circ} \mathrm{C}$ for $16 \mathrm{~h}$ after addition of $20 \mu \mathrm{L} 50 \mathrm{~mm}$ $\mathrm{NH}_{4} \mathrm{HCO}_{3}$. The digestion solution was recovered and digested peptides were extracted from the gels by sonication twice with $50 \mu \mathrm{L} 50 \%$ ACN/0.1\% TFA and twice with $50 \mu \mathrm{L}$ ACN. The digestion solution and extracts were combined and later divided into two equal aliquots. The first aliquot was further concentrated to approximately 10 $\mu \mathrm{L}$ and desalted using $\mathrm{C}_{18}$ ZipTip (Millipore Corporate, Billerica, USA). The 2nd aliquot was dried completely in a speed vacuum and subjected to SPITC derivatization.

SPITC derivatization of peptides. Chemical derivatization by SPITC was performed according to the method described by Wang et l. $^{28)}$ A SPITC solution of $10 \mathrm{mg} /$ $\mathrm{mL}$ SPITC was prepared in $20 \mathrm{mM} \mathrm{NaHCO}$ ( $\mathrm{pH}$ 8.2). Dried digested peptide mixtures were resolubilized in 8.5 $\mu \mathrm{L}$ of SPITC solution and incubated at $56^{\circ} \mathrm{C}$ for $1 \mathrm{~h}$. Reaction was stop by addition of $1 \mu \mathrm{L} 5 \%$ TFA solution. Finally, derivatized samples were desalted using $\mathrm{C}_{18}$ ZipTip (Millipore Corporate).

Mass spectrometry analysis. Desalted samples $(0.5 \mu \mathrm{L})$ were spotted onto MTP 384 target ground steel T F (Bruker Daltonics GmbH, Bremen, Germany) followed by addition of $0.5 \mu \mathrm{L}$ of matrix solution $(10 \mathrm{mg} / \mathrm{mL}$ HCCA in $50 \% \mathrm{ACN} / 0.1 \% \mathrm{TFA})$. The mixture was allowed to air dry at room temperature. MALDI-TOF MS spectra and MALDI-TOF/TOF MS spectra were acquired in the positive reflectron mode on a Bruker Daltonics Autoflex III TOF/TOF-NN without post-ionization delayed extraction. MALDI-TOF MS Spectra were acquired with the following settings: ion source $1,19 \mathrm{kV}$; ion source $2,16.6 \mathrm{kV}$; lens, $8.75 \mathrm{kV}$; reflector, $21 \mathrm{kV}$; reflector $2,9.7 \mathrm{kV}$; matrix suppression, 500 Da. Mass calibration was carried out with the peptide calibration standards (Bruker Daltonics 
GmbH). MALDI-TOF/TOF MS spectra were acquired with the following settings: ion source $1,6 \mathrm{kV}$, ion source 2, $5.3 \mathrm{kV}$; lens, $3 \mathrm{kV}$; reflector, $27 \mathrm{kV}$; reflector 2, 11.7 $\mathrm{kV}$; LIFT 1, $19 \mathrm{kV}$; LIFT 2, $4.4 \mathrm{kV}$. Precursor ion selection (PCIS) was $0.65 \%$ of parent mass. No gas was applied in the collision cell. A total of 800-1200 laser shots at $100 \mathrm{~Hz}$ were accumulated for MALDI-TOF MS and MALDI-TOF/TOF MS spectrum on both derivatized and underivatized samples.

To find derivatized peptide ions, MALDI-TOF MS spectra of underivatized and SPITC-derivatized samples were first compared. SPITC-derivatized peptide ions were identified by a $215 \mathrm{~m} / \mathrm{z}$ increase in mass from their underivatized peptide ions. Moreover, MALDI-TOF/TOF MS spectra of SPITC-derivatized peptides were preceded by the loss of $215 \mathrm{~m} / \mathrm{z}$ of SPITC and $173 \mathrm{~m} / \mathrm{z}$ of sufanilic acid. ${ }^{25)}$ PSD of SPITC-derivatized peptides resulted in highly abundant $y$-ion series, and sequences were obtained by measuring the differences between adjacent fragment ion peaks of the assumed $y$-ions series with the assistance of FlexAnalysis 3.0 (Bruker Daltonics $\mathrm{GmbH}$ ). Gaps in some sequences resulting from missing $y$-ions or low intensity ambiguous peaks were filled by possible amino acid combinations suggested by RapiDeNovo program in Biotools 3.1 (Bruker Daltonics $\mathrm{GmbH}$ ). ${ }^{25)}$

Database searches. Database searches were performed by referring to Samyn et al. ${ }^{23,24)}$ De novo-derived peptide sequences were combined in one search query and analyzed by FASTS and MS-BLAST. ${ }^{29,30)}$ The FASTS algorithm was carried out using default settings, and searches were performed against the SwissProt and NCBI Refseq proteins with BLOSUM 50 as the search matrix. The MSBLAST algorithm was performed using default settings. All mass increments of 113 Da between consecutive $y$ ions were designated as Leu. The FASTS and MSBLAST search results were considered significant if the E-score was below 1e-2 and if the resulting scores were higher than the threshold score indicated in the software, respectively. Proteins were considered as being positively identified if the 2 search algorithms yielded the same homologous protein in the first hit.

\section{RESULTS AND DISCUSSION}

\section{Protein extraction and 2-DE.}

In order to investigate the proteome of cocoa pod husk, it is necessary to establish a protocol to isolate highquality proteins. Plants contain many compounds that can interfere with 2-DE analysis ${ }^{14,22)}$ and cocoa is no exception. Cocoa pod husk contains high amounts of polyphenols (especially procyanidins), charged polysaccharides (gum), cellulose, hemicellulose, lignin and potassium. ${ }^{19-21,31)}$ Pod husk also contains a woody sclerotic layer, which can vary greatly in thickness and hardness depending on the clone. Therefore, pod husk is a recalcitrant sample and exceptionally challenging to work with. We used a phenol extraction/ammonium acetate in methanol precipitation method, because it has proven to give good results in many other recalcitrant plants such as banana, ${ }^{14)}$ olive, ${ }^{22)}$ cotton $^{32)}$ and palm date. ${ }^{33)}$

Before protein extraction, we prepared AcDP by wash- ing samples with large amounts of ice-cold acetone $(0.2 \mathrm{~g}$ of tissue: $10 \mathrm{~mL}$ of acetone) to remove mainly phenolic compounds. Further washing steps using aqueous TCA and aqueous acetone as reported in Wang et $a .^{22)}$ and $\mathrm{Pi}$ rovani et $a l{ }^{18)}$ were omitted because they resulted in a pellet that was sticky and difficult to dry. A fine powder could not be obtained by grinding this pellet, and it is necessary to obtain a fine AcDP for efficient removal of contaminants during phenol extraction. Such an observation was not reported in previous work using vegetative tissues. $^{18)}$

To analyze 2-DE images, total proteins from clones LAFI7 and ICS39 were separated by $2-\mathrm{DE}$ in the range of pI 4-7. After staining with colloidal CBB, about 700 proteins spots were visualized in both clones (Fig. 1). Protein spots were sharp, without streaking, and well-distributed along $\mathrm{p} I$ 4.5-6.5 and mass range of $100-15 \mathrm{kDa}$. The 2DE images obtained were also low in background. These results indicate that the phenol extraction/ammonium acetate in methanol precipitation method can be used to successfully eliminate most interfering compounds for 2-DE analysis from pod husk. In addition, the 2-DE proteome pattern of pod husk did not contain highly abundant protein spots such as RuBisCo in leaves that can reduce 2DE dynamic resolution.

On the other hand, other methods such as TCA/acetone were not suitable for protein extraction due to coprecipitation of gums and protein. Moreover, the method described here does not require extensive washing and sonication when preparing AcDP as reported by Pirovani et al., ${ }^{18)}$ thus shortening the extraction procedure. The 2DE produced from total protein is comparable or even better than previously reported in vegetative tissues. ${ }^{18)}$ Thus we believe that our procedure could also be used for other cocoa tissues. Finally, we also showed that lyophilization of cocoa pod husk tissue did not affect 2-DE analyses, thus making tissue storage easy as well as helping to concentrate protein. This result is consistent with a report by Carpentier et $a l .^{34)}$

\section{Identification of proteins by de novo sequencing and homology search.}

For organisms with unsequenced genomes, such as cocoa, one way to identify their proteins is to do de novo sequence analyses and cross-species homology searches. ${ }^{23,24)}$ Even when the genomes are known, de novo sequence analyses are useful because they are not affected by errors in a search databases and they can increase the confidence level of protein identification. ${ }^{35,36)}$ Nevertheless, application of MALDI for de novo sequencing is initially limited due to the low signal to noise level and spectral complexity. ${ }^{23,24)}$ This was solved by addition of SPITC to the $N$-terminal of tryptic peptides resulting in abundant sequence information-bearing $y$-ions in the MS/MS spectra (Fig. 2). Accordingly, unambiguous sequences can be deduced by simply measuring the differences between adjacent fragment ion peaks in a $y$-ion series (Fig. 2).

As an initial step toward a comprehensive cocoa pod husk proteome analysis, we excised 233 and 11 protein spots with varying spot intensities, $\mathrm{p} I$, and $M_{\mathrm{r}}$ from 2-DE gels of clones LAFI7 and ICS39, respectively. Protein 


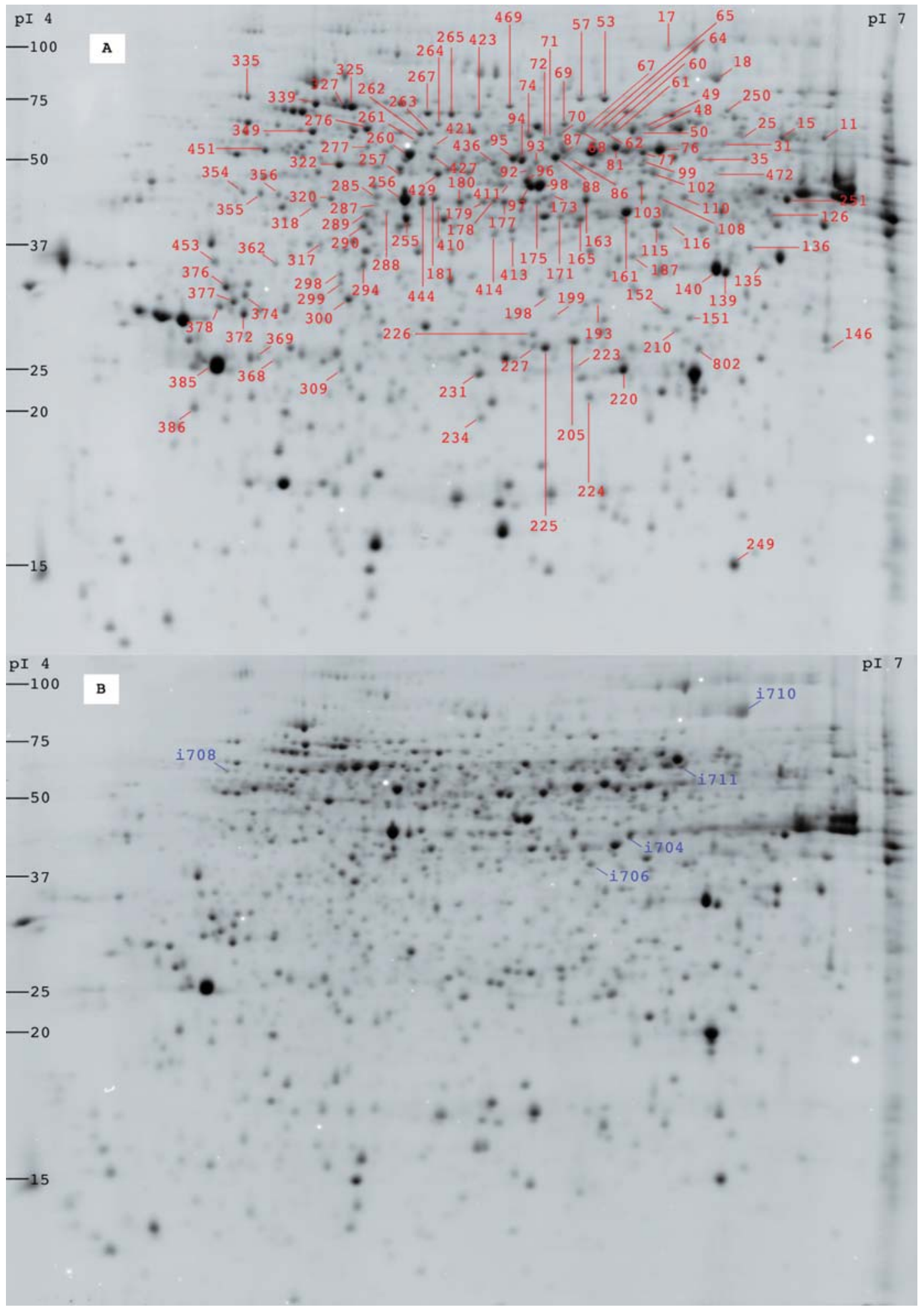

Fig. 1. 2-DE gels of protein extracted from 3-months-old pod husk of clone LAFI7 (A) and ICS39 (B).

Gels were stained with colloidal CBB G-250. Proteins identified were tagged arbitrarily and listed in Table 1. Protein spots with the letter ‘i’ were exclusive for clone ICS39.

spots exclusive for clone ICS39 were indicated by the letter 'i'. The proteins were in-gel digested by trypsin and subjected to MALDI-TOF/TOF MS analysis directly or after SPITC derivatization. After de novo sequencing and homology searches, 144 protein spots out of 244 analyzed (59\%) were successfully identified (Fig. 1, Table 1, Supplementary Tables 1(a), (b)). Previously, $32 \%$ to $76 \%$ success has been reported in other unsequenced organisms using a similar approach. ${ }^{23,24,26)}$ Therefore, we consider our result acceptable. The remaining $41 \%$ of the peptides failed to be identified due to insufficient sequence information or gaps within sequences. Similar to a previous report by Samyn et al., ${ }^{23)}$ this was most likely due to the low ion signal of the derivatized peptides. Furthermore, fragmentation of SPITC-derivatized peptides involves the loss of the SPITC group as the major fragmentation pathway, thus resulting in a decrease in the total $y$-ion series. ${ }^{36)}$ In some spots, for example 63, 323 and 424, sufficient sequence information was obtained, but homology searches resulted in scores below the threshold. These proteins may be 

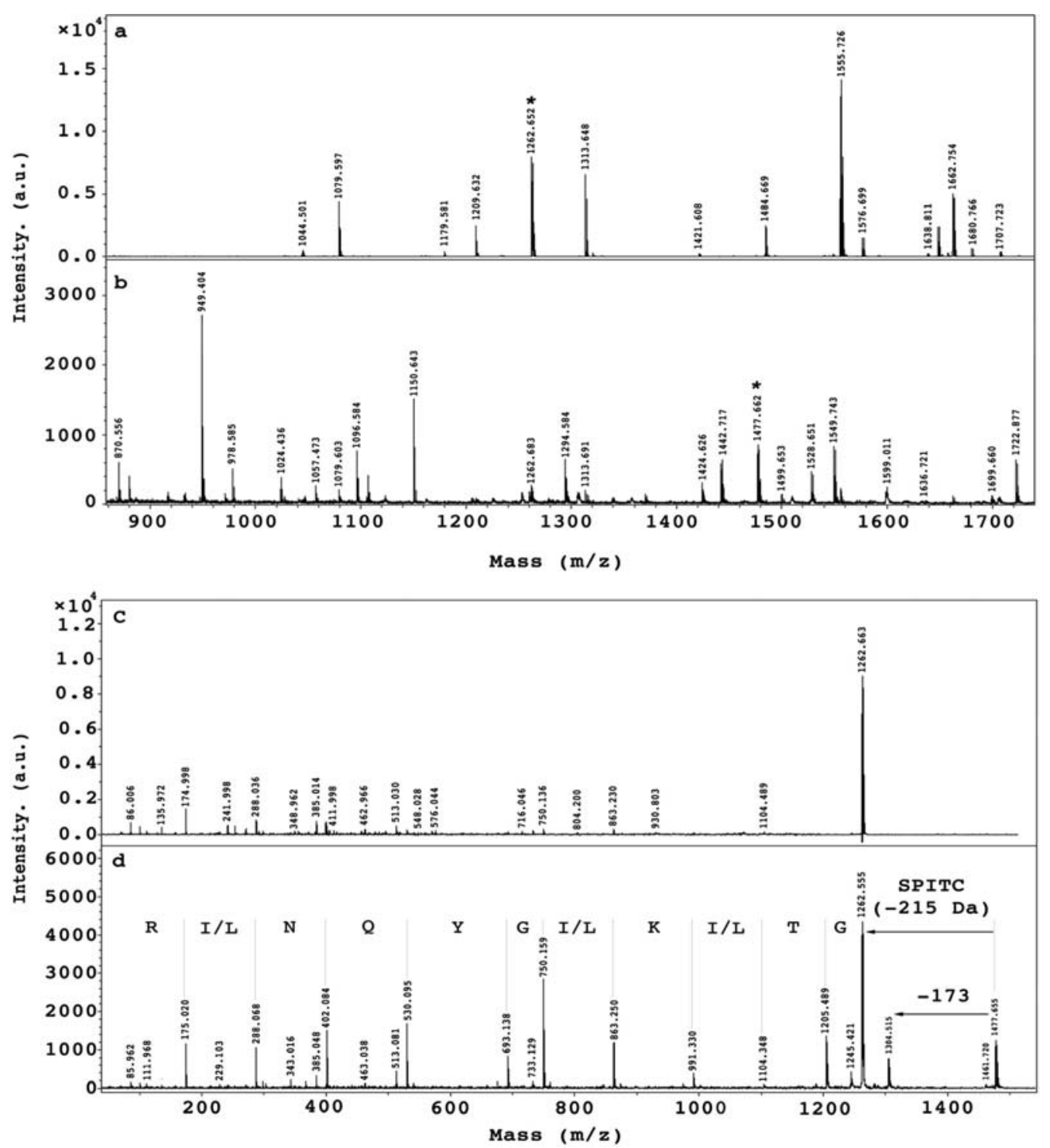

Fig. 2. MALDI-TOF MS spectra of spot 323 before (a) and after derivatization with SPITC (b). MALDI-TOF/TOF MS spectrum of the non-derivatized precursor ion at $\mathrm{m} / z, 1262$ (c) compared with SPITC-derivatized counterpart at $\mathrm{m} / \mathrm{z} 1477$ (d).

Asterisk indicate the peptide that was successfully derivatized and identified by a $215 \mathrm{Da}$ increase in precursor mass. The SPITCderivatized spectrum started with a mass loss of 215 and 173, which are characteristic for SPITC-derivatized peptides. The complete series of $y$-ions lead to confident interpretation of the spectrum. a.u. indicates arbitrary unit.

unique to cocoa pod growth and development.

\section{Classification of identified proteins.}

We classified the identified proteins according to their general function based on reports by Imin et al., ${ }^{37)}$ Faurobert et al., ${ }^{38)}$ and Baba et al. ${ }^{39)}$ The descriptions of the identified proteins are shown in Fig. 3. The majority of the identified proteins are involved in primary and energy metabolism. This class of proteins is abundant in most cells $^{37)}$ and functions as housekeeping proteins involved in general cellular processes. ${ }^{40)}$ Proteins related to glycolysis: enolase (spots 77, 88, 95), triose-phosphate isomerase (spots 146, 225), phosphoglycerate kinase (spots 163, 165, 179, i704), Calvin cycle: RuBisCo (spot 276), and TCA cycle: malate dehydrogenase (spots 115 , 187) were among those identified. Similar results were reported for developing tomato fruit ${ }^{38)}$ and Medicago truncatula embryogenic culture. ${ }^{37}$ Within this class, three intense protein spots close in $\mathrm{p} I$ and $M \mathrm{r}$ were identified as S-adenosylmethionine synthetase 1 (spots 96, 97, 98).
This enzyme catalyzes the biosynthesis of Sadenosylmethionine (Adomet) from methionine and ATP. In plants, Adomet functions as a precursor in the biosynthesis of the phytohormone ethylene and serves as a propylamine group donor after decarboxylation in the biosynthesis of polyamines. ${ }^{41)}$ Increases in polyamine levels in tomato pericarp have been associated with slow ripening due to inhibition of ethylene production by polyamines. ${ }^{42)}$ Because cocoa fruit has non-climacteric ripening, whereby its ripening is not controlled by ethylene, the high abundance of this enzyme in pod husk may be associated with the production of polyamines. S-adenosylmethionine synthetase is also required as a cofactor for lignin biosynthesis. ${ }^{43)}$

Plants produce a broad variety of secondary metabolic compounds such as lignins, flavonoids, and phytoalexins. These compounds are produced by the phenylpropanoid pathway and have important roles in plant physiology. ${ }^{44)}$ We have identified six proteins (spots 136, 140, 173, 177, 309 , i706) as members of this pathway. Two of the pro- 
Table 1. Protein identification by de novo sequencing of SPITC-derivatized peptides from clones LAFI7 and ICS39.

\begin{tabular}{|c|c|c|c|c|c|c|c|c|}
\hline $\operatorname{Spot}^{\mathrm{a}}$ & $\begin{array}{c}\text { Accession } \\
\text { Number }^{\mathrm{b}}\end{array}$ & Protein $^{c}$ & $\mathrm{PM}^{\mathrm{d}}$ & Organism & $E$-score ${ }^{\mathrm{f}}$ & $\begin{array}{c}\text { Exp. } \\
M \mathrm{r} / \mathrm{p} I^{\mathrm{g}}\end{array}$ & $\begin{array}{c}\text { Theo. } \\
M \mathrm{r} / \mathrm{p} I^{\mathrm{h}}\end{array}$ & Class. ${ }^{\mathrm{i}}$ \\
\hline \multicolumn{9}{|c|}{ (a) LAFI7 } \\
\hline 11 & gil 113363 & Alcohol dehydrogenase 1 & $2 / 3$ & 26 Petunia $\times$ hybrida & $4.7 \mathrm{e}-03$ & $57.0 / 6.8$ & $41.6 / 6.2$ & ME \\
\hline 15 & gil2494175 & Glutamate decarboxylase 2 & $2 / 2$ & 25 Arabidopsis thaliana & $7.8 \mathrm{e}-06$ & $57.2 / 6.6$ & $56.1 / 5.3$ & ME \\
\hline 17 & gil6015065 & Elongation factor 2 & $1 / 1$ & 16 Beta vulgaris & $3.5 \mathrm{e}-09$ & $100.7 / 6.3$ & $93.9 / 5.9$ & PSP \\
\hline 18 & gil8134568 & 5-Methyltetrahydropteroyltriglutamate & $6 / 7$ & 76 Mesembryanthemum crystallinum & $3.3 e-42$ & $84.0 / 6.4$ & $84.8 / 5.9$ & ME \\
\hline 25 & gil3914360 & Phospholipase D $\alpha 1$ & $3 / 3$ & 33 Pimpinella brachycarpa & $4.6 \mathrm{e}-05$ & $57.5 / 6.5$ & $91.7 / 5.7$ & ME \\
\hline 31 & gil51701894 & Tubulin $\beta-1$ chain & $1 / 1$ & 12 Encephalitozoon cuniculi & $9.9 \mathrm{e}-04$ & $54.9 / 6.5$ & $49.1 / 4.9$ & CS \\
\hline 35 & gil3914449 & Protease regulatory subunit 7 & $4 / 5$ & 58 Prunus persica & $6.7 e-34$ & $50.2 / 6.4$ & $47.6 / 6.4$ & PSP \\
\hline 48 & gil2499489 & $\begin{array}{l}\text { Pyrophosphate-fructose 6-phosphate 1-phosphotransferase } \\
\text { subunit }\end{array}$ & $3 / 3$ & 32 Ricinus communis & $6.3 e-15$ & $60.3 / 6.3$ & $60.1 / 6.2$ & ME \\
\hline 49 & gil10720307 & T-complex protein 1 subunit $\zeta$ & $2 / 2$ & 31 Schizosaccharomyces pombe & $8.1 \mathrm{e}-08$ & $61.9 / 6.2$ & $58.5 / 5.9$ & PSP \\
\hline 50 & gil6225542 & Ketol-acid reductoisomerase, chloroplastic & $3 / 3$ & 42 Pisum sativum & $7.1 \mathrm{e}-20$ & $58.8 / 6.2$ & $57.8 / 5.9$ & ME \\
\hline 53 & gil2501356 & Transketolase, chloroplastic & $2 / 2$ & 22 Solanum tuberosum & $6.2 \mathrm{e}-13$ & $75.0 / 6.1$ & $72.9 / 5.5$ & ME \\
\hline 57 & gil2501356 & Transketolase, chloroplastic & $2 / 2$ & 22 Solanum tuberosum & $1.3 \mathrm{e}-12$ & $75.1 / 6.0$ & $72.9 / 5.5$ & ME \\
\hline 60 & gil2499489 & $\begin{array}{l}\text { Pyrophosphate-fructose 6-phosphate 1-phosphotransferase } \\
\text { subunit }\end{array}$ & $2 / 4$ & 36 Ricinus communis & $9.1 \mathrm{e}-10$ & $61.6 / 6.1$ & $60.1 / 6.2$ & ME \\
\hline 61 & gil2499489 & $\begin{array}{l}\text { Pyrophosphate-fructose 6-phosphate 1-phosphotransferase } \\
\text { subunit }\end{array}$ & $5 / 5$ & 51 Ricinus communis & $6.1 \mathrm{e}-35$ & $59.8 / 6.1$ & $60.1 / 6.2$ & ME \\
\hline 62 & gil25452981 & Glucose-6-phosphate-dehydrogenase & $4 / 4$ & 44 Arabidopsis thaliana & $1.8 \mathrm{e}-24$ & $58.5 / 6.1$ & $59.2 / 8.4$ & ME \\
\hline 64 & gil54038948 & $\begin{array}{l}\text { Phosphoribosylaminoimidazolecarboxamide formyltrans- } \\
\text { ferase }\end{array}$ & $1 / 2$ & 23 Streptococcus agalactiae & $6.4 \mathrm{e}-07$ & $59.8 / 6.1$ & $56.1 / 4.9$ & ME \\
\hline 65 & gil6225542 & ketol-acid reductoisomerase chloroplastic & $1 / 1$ & 19 Spinacia oleracea & $5.0 \mathrm{e}-06$ & $59.7 / 6.0$ & $57.8 / 5.9$ & ME \\
\hline 67 & gil135535 & T-complex protein $1 \alpha$ subunit & $2 / 3$ & 38 Arabidopsis thaliana & $3.5 \mathrm{e}-13$ & $60.7 / 6.0$ & $59.2 / 5.9$ & PSP \\
\hline 68 & gil146286092 & Coatomer subunit $\delta$ & $1 / 3$ & 29 Arabidopsis thaliana & $7.4 \mathrm{e}-06$ & $59.0 / 6.0$ & $57.7 / 5.6$ & MT \\
\hline 69 & gil3914394 & 2,3-biphosphoglycerate-independent phosphoglycerate mutase & $4 / 4$ & 52 Mesembryanthemum crystallinum & $7.1 \mathrm{e}-26$ & $61.8 / 5.9$ & $61.2 / 5.4$ & ME \\
\hline 70 & gil75115272 & ketol-acid reductoisomerase & $3 / 3$ & 37 Spinacia oleracea & $9.3 e-21$ & $58.2 / 5.9$ & $57.4 / 5.5$ & ME \\
\hline 71 & gil543865 & ATP synthase subunit $\alpha$, mitochondria & $2 / 3$ & 33 Beta vulgaris & $2.8 \mathrm{e}-13$ & $56.7 / 5.9$ & $54.9 / 6.0$ & MT \\
\hline 72 & gil266346 & ketol-acid reductoisomerase & $2 / 4$ & 46 Spinacia oleracea & $4.8 \mathrm{e}-10$ & $56.9 / 5.8$ & $56.9 / 5.6$ & ME \\
\hline 74 & gil74996549 & T-complex protein 1 subunit $\beta$ & $2 / 3$ & 34 Arabidopsis thaliana & $2.5 \mathrm{e}-03$ & $57.7 / 5.8$ & $58.0 / 5.8$ & PSP \\
\hline 76 & gil1172858 & Ribulose-1,5-biphosphate carboxylase large chain & $4 / 4$ & 42 Cibotium barometz & $8.4 \mathrm{e}-30$ & $52.3 / 6.3$ & $45.9 / 6.2$ & ME \\
\hline 77 & gil14423687 & Enolase 2 & $4 / 4$ & 51 Hevea brasiliensis & $5.6 e-16$ & $52.1 / 6.2$ & $47.9 / 5.9$ & ME \\
\hline 81 & gil543865 & ATP synthase subunit $\alpha$ & $8 / 8$ & 80 Beta vulgaris & $1.6 e-58$ & $53.1 / 6.1$ & $54.9 / 6.0$ & MT \\
\hline 86 & gil6094242 & Putative selenium-binding protein & $3 / 4$ & 59 Arabidopsis thaliana & $1.0 \mathrm{e}-22$ & $50.0 / 5.9$ & $54.1 / 5.4$ & DS \\
\hline 87 & gil543865 & ATP synthase subunit $\alpha$, mitochondrial & $2 / 4$ & 49 Beta vulgaris & $1.1 \mathrm{e}-12$ & $53.4 / 5.9$ & $54.9 / 6.0$ & MT \\
\hline 88 & gil14423687 & Enolase 2 & $4 / 5$ & 51 Hevea brasiliensis & $2.6 e-19$ & $50.5 / 5.9$ & $47.9 / 5.9$ & ME \\
\hline 92 & gil25453205 & Peroxidase 12 & $4 / 5$ & 64 Arabidopsis thaliana & $8.6 e-19$ & $48.3 / 5.8$ & $36.1 / 8.4$ & DS \\
\hline 93 & gil115646 & $\alpha$-S1-casein & $3 / 6$ & 54 Bos taurus & $4.5 \mathrm{e}-20$ & $49.5 / 5.8$ & $23.0 / 4.9$ & $\mathrm{U}$ \\
\hline 94 & gil12585489 & UDP-glucose pyrophosphorylase & $3 / 3$ & 43 Musa acuminata & $4.0 \mathrm{e}-35$ & $49.5 / 5.8$ & $47.9 / 5.6$ & ME \\
\hline 95 & gil1169534 & Enolase & $4 / 6$ & 77 Ricinus communis & $5.3 e-32$ & $50.1 / 5.7$ & $47.9 / 5.6$ & ME \\
\hline 96 & gil400246 & $S$-adenosylmethionine synthetase I & $2 / 4$ & 53 Petroselinum crispum & $9.4 \mathrm{e}-19$ & $46.5 / 5.8$ & $25.7 / 7.9$ & ME \\
\hline 97 & gil400246 & $S$-adenosylmethionine synthetase I & $3 / 3$ & 34 Petroselinum crispum & $2.3 e-27$ & $45.5 / 5.8$ & $25.7 / 7.9$ & ME \\
\hline 98 & gil400246 & $S$-adenosylmethionine synthetase I & $3 / 4$ & 56 Ostreococcus lucimarin & $6.9 \mathrm{e}-25$ & $45.6 / 5.8$ & $25.7 / 7.9$ & ME \\
\hline 99 & gil68052019 & Biotin carboxylase & $2 / 6$ & 54 Populus euphratica & $1.3 \mathrm{e}-06$ & $49.9 / 6.2$ & $42.9 / 6.3$ & ME \\
\hline 102 & gil20141399 & 3-oxoacyl-[acyl-carrier-protein] synthase & $3 / 7$ & 69 Arabidopsis thaliana & $2.7 \mathrm{e}-17$ & $47.7 / 6.3$ & $45.1 / 6.2$ & ME \\
\hline 103 & gil73919692 & GDP-D-mannose 3,5-epimerase & $4 / 6$ & 62 Arabidopsis thaliana & $6.9 \mathrm{e}-26$ & $46.3 / 6.2$ & $42.8 / 5.9$ & ME \\
\hline 108 & gil189044723 & Elongation factor $\mathrm{Tu} 2$ & $2 / 3$ & 37 Alkaliphilus metalliredigens & $1.1 \mathrm{e}-16$ & $44.2 / 6.3$ & $43.7 / 5.0$ & PSP \\
\hline 110 & gil122064253 & Isocitrate dehydrogenase [NAD] regulatory subunit 1 & $3 / 3$ & 30 Arabidopsis thaliana & $1.4 \mathrm{e}-12$ & $44.1 / 6.4$ & $36.9 / 6.4$ & ME \\
\hline 115 & gil126896 & Malate dehydrogenase, mitochondrial & $3 / 6$ & 67 Citrullus lanatus & $3.3 e-13$ & $40.2 / 6.3$ & $33.2 / 6.3$ & ME \\
\hline 116 & gil1168493 & Arginase & $6 / 6$ & 56 Arabidopsis thaliana & $1.5 \mathrm{e}-31$ & $40.2 / 6.3$ & $37.3 / 6.1$ & ME \\
\hline 126 & gil1352461 & IN2-2 protein & $2 / 5$ & 59 Zea mays & $7.8 \mathrm{e}-16$ & $41.6 / 6.6$ & $33.8 / 8.9$ & $\mathrm{U}$ \\
\hline 135 & gil51701846 & $26 \mathrm{~S}$ proteasome non-ATPase regulatory subunit 14 & $3 / 4$ & 27 Arabidopsis thaliana & $3.1 \mathrm{e}-10$ & $35.2 / 6.6$ & $34.3 / 6.3$ & PSP \\
\hline 136 & gil1708422 & Isoflavone reductase homolog & $2 / 3$ & 32 Solanum tuberosum & $9.6 e-13$ & $37.3 / 6.5$ & $33.9 / 6.1$ & SM \\
\hline 139 & gil75337884 & Annexin D1 & $3 / 6$ & 66 Arabidopsis thaliana & $1.9 \mathrm{e}-13$ & $34.2 / 6.5$ & $36.2 / 5.2$ & ST \\
\hline 140 & gil1708421 & Isoflavone reductase homolog IRL & $3 / 3$ & 31 Zea mays & $1.4 \mathrm{e}-15$ & $34.9 / 6.4$ & $32.9 / 5.7$ & SM \\
\hline 146 & gil1351279 & Triose-phosphate isomerase, cytosolic & $3 / 3$ & 36 Petunia $\times$ hybrida & $6.0 \mathrm{e}-21$ & $26.7 / 6.8$ & $27.1 / 5.5$ & ME \\
\hline 151 & gil75331395 & Probable calcium-binding protein CML49 & $1 / 3$ & 29 Arabidopsis thaliana & $8.5 \mathrm{e}-06$ & $29.6 / 6.4$ & $35.3 / 6.4$ & $\mathrm{U}$ \\
\hline 152 & gil75331395 & Probable calcium-binding protein CML49 & $2 / 2$ & 21 Arabidopsis thaliana & $1.2 \mathrm{e}-12$ & $30.3 / 6.3$ & $35.3 / 6.3$ & $\mathrm{U}$ \\
\hline 161 & gil121345 & Glutamine synthetase PR-2 & $2 / 2$ & 29 Phaseolus vulgaris & $9.6 e-13$ & $41.8 / 6.2$ & $39.2 / 5.4$ & ME \\
\hline 163 & gil2499498 & Phosphoglycerate kinase, cytosolic & $3 / 5$ & 64 Nicotiana tabacum & $5.1 \mathrm{e}-26$ & $43.7 / 6.0$ & $42.4 / 5.7$ & ME \\
\hline 165 & gil2499499 & Phosphoglycerate kinase, cytosolic & $3 / 3$ & 44 Arabidopsis thaliana & $5.3 e-30$ & $40.7 / 6.0$ & $42.4 / 5.8$ & ME \\
\hline 171 & gil229891797 & $\alpha-1,4$-glucan-protein synthase [UDP-forming] & $1 / 2$ & 19 Phoenix dactylifera & $8.8 \mathrm{e}-08$ & $41.4 / 5.9$ & $68.5 / 7.8$ & $\mathrm{CS}$ \\
\hline 173 & gil30173108 & Leucoanthocyanidin dioxygenase & $1 / 1$ & 17 Arabidopsis thaliana & $7.0 \mathrm{e}-08$ & $44.5 / 5.9$ & $40.4 / 5.2$ & SM \\
\hline 175 & gil75163801 & L,L-Diaminopimelate aminotransferase & $7 / 8$ & 37 Arabidopsis thaliana & $3.9 \mathrm{e}-59$ & $43.4 / 5.8$ & $46.5 / 6.4$ & ME \\
\hline 177 & gil1345655 & Cinnamyl alcohol dehydrogenase 4 & $2 / 2$ & 27 Arabidopsis thaliana & $3.9 \mathrm{e}-13$ & $43.4 / 5.7$ & $39.1 / 5.3$ & SM \\
\hline 178 & gil119194 & Elongation factor $\mathrm{Tu}$, chloroplastic & $5 / 5$ & 59 Arabidopsis thaliana & $3.2 \mathrm{e}-34$ & $43.7 / 5.7$ & $44.7 / 5.3$ & PSP \\
\hline 179 & gil12644295 & Phosphoglycerate kinase, chloroplastic & $2 / 2$ & 27 Arabidopsis thaliana & $6.4 \mathrm{e}-17$ & $43.4 / 5.6$ & $42.6 / 5.0$ & ME \\
\hline 180 & gil231502 & Actin-85C & $2 / 3$ & 26 Solanum tuberosum & $9.3 e-13$ & $43.4 / 5.5$ & $21.7 / 5.9$ & CS \\
\hline 181 & gil231503 & Actin-85C & $3 / 4$ & 37 Solanum tuberosum & $1.1 \mathrm{e}-19$ & $43.9 / 5.5$ & $21.7 / 5.9$ & CS \\
\hline 187 & gil75313643 & Malate dehydrogenase, chloroplastic & $2 / 2$ & 23 Arabidopsis thaliana & $2.2 \mathrm{e}-06$ & $36.3 / 6.2$ & $34.1 / 5.7$ & ME \\
\hline 193 & gil74683233 & Protein transport SEC13 & $1 / 3$ & 32 Filobasidiella neoformans & $2.3 \mathrm{e}-05$ & $31.4 / 6.0$ & $36.8 / 5.8$ & MT \\
\hline 198 & gil74996477 & Probable 3-hydroxyisobutyrate dehydrogenase & $2 / 3$ & 30 Dictyostelium discoideum & $1.2 \mathrm{e}-06$ & $31.8 / 5.9$ & $33.9 / 8.8$ & ME \\
\hline 199 & gil51316816 & Photosystem I assembly protein Ycf4 & $1 / 2$ & 26 Adiantum capillus-veneris & $7.6 \mathrm{e}-03$ & $29.7 / 5.9$ & $20.8 / 9.3$ & ME \\
\hline 205 & gil1351963 & L-Ascorbate peroxidase, cytosolic & $4 / 4$ & 45 Pisum sativum & $9.2 \mathrm{e}-22$ & $27.4 / 5.9$ & $27.1 / 5.5$ & DS \\
\hline 210 & gil1717752 & Tropinone reductase 1 & $3 / 3$ & 46 Datura stramonium & $2.2 \mathrm{e}-12$ & $28.5 / 6.3$ & $29.6 / 6.1$ & SM \\
\hline 220 & gil225446793 & Glutathione S-transferase 3 & $2 / 3$ & 25 Vitis vinifera & $2.6 \mathrm{e}-05$ & $24.9 / 6.2$ & $25.0 / 5.8$ & DS \\
\hline 223 & gil75334429 & GSH-dependent dehydroascorbate reductase 1 & $2 / 3$ & 31 Arabidopsis thaliana & $4.9 \mathrm{e}-07$ & $25.2 / 6.0$ & $23.6 / 5.6$ & ME \\
\hline 224 & gil17380179 & $20 S$ proteasome $\beta$ subunit $D$, type 2 & $4 / 6$ & 53 Arabidopsis thaliana & $4.0 \mathrm{e}-26$ & $23.2 / 6.0$ & $22.5 / 6.0$ & PSP \\
\hline
\end{tabular}




\begin{tabular}{|c|c|c|c|c|c|c|c|c|}
\hline Spot $^{\mathrm{a}}$ & $\begin{array}{c}\text { Accession } \\
\text { Number }^{\mathrm{b}}\end{array}$ & Protein $^{c}$ & $\mathrm{PM}^{\mathrm{d}}$ & Organism & $E$-score $^{\mathrm{f}}$ & $\begin{array}{c}\text { Exp. } \\
M \mathrm{r} / \mathrm{p} I^{g}\end{array}$ & $\begin{array}{c}\text { Theo. } \\
M \mathrm{r} / \mathrm{p} I^{\mathrm{h}}\end{array}$ & Class. $^{\mathrm{i}}$ \\
\hline 225 & gil1360571 & Triose-phosphate isomerase, cytosolic & $5 / 5$ & 327 Coptis japonica & $2.4 \mathrm{e}-32$ & $26.8 / 5.8$ & $39.4 / 5.6$ & ME \\
\hline 226 & gil22096383 & Uncharacterized protein & $1 / 1$ & 16 Arabidopsis thaliana & $2.6 \mathrm{e}-08$ & $28.1 / 5.8$ & $34.9 / 8.4$ & $\mathrm{U}$ \\
\hline 227 & gil1172601 & Probable proteasome subunit $\alpha$ type- 4 & $1 / 1$ & 9 Schizosaccharomyces pombe & $2.2 \mathrm{e}-03$ & $27.0 / 5.8$ & $27.9 / 5.9$ & PSP \\
\hline 231 & gil12643263 & Chaperonin 10 & $2 / 3$ & 30 Arabidopsis thaliana & $1.1 \mathrm{e}-10$ & $24.7 / 5.6$ & $21.4 / 5.2$ & PSP \\
\hline 234 & gil73921673 & Allene oxide cyclase 3 , chloroplastic & $2 / 2$ & 21 Arabidopsis thaliana & $2.6 \mathrm{e}-04$ & $21.9 / 5.6$ & $22.4 / 8.7$ & $\mathrm{ME}$ \\
\hline 249 & gil1346675 & Nucleoside diphosphate kinase B & $3 / 3$ & 38 Flaveria bidentis & $3.2 \mathrm{e}-27$ & $15.0 / 6.5$ & $16.1 / 5.9$ & ME \\
\hline 250 & gil14285792 & T-complex protein 1 subunit $\gamma$ & $2 / 2$ & 21 Thalassiosira weissflogii & $1.3 \mathrm{e}-05$ & $67.9 / 6.5$ & $61.7 / 5.6$ & PSP \\
\hline 251 & gil109909540 & Formate dehydrogenase 1 , mitochondrial & $6 / 9$ & 93 Oryza sativa & $3.9 \mathrm{e}-41$ & $44.6 / 6.7$ & $39.3 / 6.2$ & ME \\
\hline 255 & gil30315948 & Caffeic acid 3-O-methyltransferase & $3 / 3$ & 31 Capsicum annuит & $1.8 \mathrm{e}-18$ & $41.2 / 5.4$ & $39.4 / 5.6$ & ME \\
\hline 256 & gil231502 & Actin-85C & $2 / 2$ & 20 Solanum tuberosum & $7.3 e-12$ & $43.3 / 5.4$ & $21.7 / 5.9$ & $\mathrm{CS}$ \\
\hline 257 & gil2500522 & Eukaryotic initiation factor $4 \mathrm{~A}$ & $4 / 4$ & 45 Zea mays & $1.3 \mathrm{e}-20$ & $47.7 / 5.3$ & $46.5 / 5.4$ & PSP \\
\hline 260 & gil26391492 & ATP synthase subunit $\beta-2$, mitochondrial & $2 / 2$ & 22 Arabidopsis thaliana & $2.6 \mathrm{e}-06$ & $51.5 / 5.4$ & $54.2 / 5.4$ & MT \\
\hline 261 & gil189045124 & Glucose-6-phosphate isomerase & $2 / 3$ & 32 Microcystis aeruginosa & $1.4 \mathrm{e}-03$ & $55.5 / 5.4$ & $58.1 / 5.8$ & ME \\
\hline 262 & gil21759093 & Betaine aldehyde dehydrogenase 1 & $5 / 5$ & 53 Zea mays & $8.5 \mathrm{e}-24$ & $58.5 / 5.4$ & $53.7 / 5.2$ & ME \\
\hline 263 & gil62900360 & Importin subunit $\alpha-1 \mathrm{a}$ & $3 / 3$ & 42 Oryza sativa & $5.3 e-16$ & $58.7 / 5.4$ & $57.6 / 5.1$ & MT \\
\hline 264 & gil585451 & NAD-dependent malic enzyme $62 \mathrm{kDa}$ isoform, mitochondrial & $3 / 4$ & 57 Solanum tuberosum & $8.8 \mathrm{e}-30$ & $62.0 / 5.5$ & $66.1 / 5.3$ & ME \\
\hline 265 & gil401322 & V-type proton ATPase catalytic subunit A & $7 / 7$ & 103 Gossypium hirsutum & $3.2 \mathrm{e}-64$ & $66.8 / 5.5$ & $68.5 / 5.4$ & MT \\
\hline 267 & gil399940 & Heat shock $70 \mathrm{kDa}$ protein, mitochondrial & $3 / 3$ & 36 Phaseolus vulgaris & $2.2 \mathrm{e}-20$ & $66.3 / 5.4$ & $67.0 / 5.3$ & DS \\
\hline 276 & gil2506277 & RuBisCO subunit binding-protein $\beta$ subunit, chloroplastic & $4 / 4$ & 53 Pisum sativum & $2.2 \mathrm{e}-26$ & $60.2 / 5.2$ & $57.9 / 5.3$ & ME \\
\hline 277 & gil190358177 & ATP synthase $\alpha$ subunit, chloroplast & $9 / 13$ & 140 Illicium oligandrum & $2.8 \mathrm{e}-76$ & $53.9 / 5.2$ & $55.4 / 5.4$ & MT \\
\hline 285 & gil1703131 & Actin 12 & $3 / 4$ & 40 Arabidopsis thaliana & $2.0 \mathrm{e}-24$ & $44.1 / 5.3$ & $41.8 / 5.4$ & $\mathrm{CS}$ \\
\hline 287 & gil21759255 & 3 -isopropylmalate dehydrogenase 2 & $3 / 3$ & 25 Arabidopsis thaliana & $4.0 \mathrm{e}-10$ & $43.1 / 5.3$ & $39.8 / 5.2$ & ME \\
\hline 288 & gil399785 & Glutamate-1-semialdehyde 2,1-aminomutase, chloroplastic & $2 / 2$ & 20 Nicotiana tabacum & $1.0 \mathrm{e}-07$ & $42.1 / 5.3$ & $50.9 / 6.4$ & ME \\
\hline 289 & gil75261432 & Succinyl-CoA ligase [GDP-forming] subunit $\beta$ & $3 / 3$ & 28 Vitis vinifera & $1.1 \mathrm{e}-13$ & $41.8 / 5.2$ & $42.1 / 5.2$ & ME \\
\hline 290 & gil17366963 & Adenosine kinase 2 & $2 / 3$ & 36 Arabidopsis thaliana & $1.3 \mathrm{e}-13$ & $40.0 / 5.2$ & $37.9 / 5.1$ & ME \\
\hline 294 & gil2493895 & Cysteine synthase & $3 / 3$ & 34 Citrullus lanatus & $5.4 \mathrm{e}-23$ & $35.3 / 5.2$ & $34.3 / 6.3$ & PSP \\
\hline 298 & gil148872800 & DNA-damage-repair/toleration protein & $1 / 1$ & 18 Oryza sativa & $7.9 \mathrm{e}-09$ & $34.3 / 5.1$ & $33.2 / 5.1$ & DS \\
\hline 299 & gil18202458 & $\alpha$-Soluble NSF attachment protein & $3 / 3$ & 34 Vitis vinifera & $1.4 \mathrm{e}-18$ & $33.3 / 5.1$ & $32.5 / 4.9$ & MT \\
\hline 300 & gil11134054 & Oxygen-evolving enhancer protein 1 & $3 / 4$ & 50 Nicotiana tabacum & $6.1 \mathrm{e}-21$ & $31.5 / 5.2$ & $26.7 / 5.1$ & ME \\
\hline 309 & gil224146220 & Chalcone isomerase-like protein & $3 / 3$ & 36 Populus trichocarpa & $4.2 \mathrm{e}-16$ & $25.0 / 5.1$ & $23.3 / 5.0$ & SM \\
\hline 317 & gil461461 & Enoyl-[acyl-carrier-protein] reductase & $2 / 2$ & 18 Brassica napus & $3.4 \mathrm{e}-08$ & $37.8 / 5.1$ & $32.9 / 5.4$ & ME \\
\hline 318 & gil8928330 & 40S Ribosomal protein SA (p40) & $3 / 3$ & 29 Daucus carota & $4.7 \mathrm{e}-17$ & $43.0 / 5.0$ & $32.5 / 4.9$ & PSP \\
\hline 320 & gil225464635 & Hypothetical protein & $3 / 5$ & 43 Vitis vinifera & $6.6 \mathrm{e}-11$ & $43.9 / 5.1$ & $40.6 / 5.0$ & $\mathrm{U}$ \\
\hline 322 & gil54036493 & Tubulin $\alpha$-2 chain; $\alpha$-2-tubulin & $6 / 7$ & 80 Gossypium hirsutum & $2.1 \mathrm{e}-38$ & $49.1 / 5.1$ & $49.5 / 4.9$ & $\mathrm{CS}$ \\
\hline 325 & gil229464991 & Heat shock $70 \mathrm{kDa}$ protein & $4 / 4$ & 48 Zea mays & $2.9 \mathrm{e}-32$ & $69.7 / 5.2$ & $70.6 / 5.2$ & DS \\
\hline 327 & gil123592 & Heat shock $70 \mathrm{kDa}$ protein & $3 / 3$ & 37 Leishmania major & $7.2 \mathrm{e}-22$ & $70.2 / 5.1$ & $56.5 / 6.5$ & DS \\
\hline 335 & gil1708311 & Stromal $70 \mathrm{kDa}$ heat shock-related protein & $4 / 7$ & 72 Spinacia oleracea & $4.3 e-31$ & $76.0 / 4.8$ & $64.9 / 4.9$ & DS \\
\hline 339 & gil123656 & Chloroplast envelope membrane $70 \mathrm{kDa}$ heat shock protein & n $3 / 3$ & 34 Spinacia oleracea & $1.6 \mathrm{e}-22$ & $72.0 / 5.0$ & $71.6 / 5.4$ & DS \\
\hline 349 & gil11133775 & Protein disulfide isomerase & $2 / 2$ & 21 Ricinus communis & $5.3 \mathrm{e}-06$ & $59.2 / 5.0$ & $53.0 / 4.9$ & PSP \\
\hline 354 & gil223635791 & Transaldolase & $1 / 3$ & 32 Capsicum аппиит & $5.7 \mathrm{e}-06$ & $44.9 / 4.8$ & $26.3 / 8.6$ & ME \\
\hline 355 & gil123142886 & Transaldolase & $3 / 3$ & 34 Frankia alni & $3.2 \mathrm{e}-10$ & $44.7 / 4.8$ & $40.0 / 5.8$ & ME \\
\hline 356 & gil123142886 & Transaldolase & $3 / 3$ & 34 Frankia alni & $3.2 \mathrm{e}-10$ & $44.6 / 4.9$ & $40.0 / 5.8$ & ME \\
\hline 362 & gil12229892 & Proteasome subunit $\alpha$ type-1-B & $3 / 4$ & 48 Arabidopsis thaliana & $8.5 \mathrm{e}-25$ & $35.5 / 4.9$ & $30.4 / 5.0$ & PSP \\
\hline 368 & gil1345698 & Chlorophyll-a/b binding protein 151 & $2 / 3$ & 28 Gossypium hirsutum & $1.8 \mathrm{e}-11$ & $25.8 / 4.9$ & $24.7 / 5.0$ & ME \\
\hline 369 & gil115777 & Chlorophyll-a/b binding protein, chloroplastic & $1 / 3$ & 29 Silene latifolia & $2.4 \mathrm{e}-04$ & $26.1 / 4.8$ & $22.0 / 5.0$ & ME \\
\hline 372 & gil1168191 & $14-3-3$ protein 4 & $4 / 4$ & 48 Solanum lypersicum & $5.4 \mathrm{e}-18$ & $30.0 / 4.8$ & $29.3 / 4.7$ & $\mathrm{ST}$ \\
\hline 374 & gil26454610 & $14-3-3$ protein 8 & $3 / 4$ & 37 Pseudotsuga menziesii & $3.0 \mathrm{e}-21$ & $32.0 / 4.8$ & $29.5 / 4.6$ & ST \\
\hline 376 & gil12230867 & 14-3-3-like protein GF14 $\omega$ & $5 / 6$ & 62 Arabidopsis thaliana & $1.9 \mathrm{e}-28$ & $32.8 / 4.7$ & $29.2 / 4.7$ & ST \\
\hline 377 & gil26454609 & $14-3-3$ protein 7 & $4 / 6$ & 62 Solanum lycopersicum & $3.8 \mathrm{e}-16$ & $31.2 / 4.7$ & $28.8 / 5.0$ & ST \\
\hline 378 & gil12230867 & 14-3-3-like protein GF14 $\omega$ & $5 / 5$ & 60 Arabidopsis thaliana & $1.1 \mathrm{e}-27$ & $30.7 / 4.7$ & $29.2 / 4.7$ & ST \\
\hline 385 & gil75294319 & 14-3-3-like protein GF14-C & $2 / 4$ & 34 Oryza sativa & $8.7 \mathrm{e}-09$ & $25.0 / 4.7$ & $28.8 / 4.8$ & ST \\
\hline 386 & gil9979193 & Translationally-controlled tumor protein & $1 / 1$ & 9 Vitis vinifera & $2.2 \mathrm{e}-03$ & $22.5 / 4.6$ & $18.8 / 4.7$ & $\mathrm{U}$ \\
\hline 410 & gil12585487 & V-type H-ATPase subunit C & $2 / 3$ & 30 Hordeum vulgare & $2.7 \mathrm{e}-17$ & $42.6 / 5.5$ & $40.0 / 6.1$ & MT \\
\hline 411 & gil75146893 & Bifunctional dihydroflavanol 4-reductase & $3 / 3$ & 34 Pyrus communis & $5.2 \mathrm{e}-16$ & $46.4 / 5.7$ & $38.9 / 5.9$ & SM \\
\hline 413 & gil75038951 & $\alpha$-S1-casein precursor & $1 / 1$ & 10 Bubalus bubalis & $1.5 \mathrm{e}-03$ & $38.7 / 5.8$ & $22.8 / 4.8$ & $\mathrm{U}$ \\
\hline 414 & gil6225258 & Aspartate semialdehyde dehydrogenase & $2 / 2$ & 23 Aquifex aeolicus & $1.8 \mathrm{e}-06$ & $39.0 / 5.7$ & $37.8 / 6.0$ & $\mathrm{ME}$ \\
\hline 421 & gil14548089 & Inositol-3-phosphate synthase & $3 / 3$ & 41 Hordeum vulgare & $7.7 e-29$ & $53.7 / 5.5$ & $56.2 / 5.5$ & $\mathrm{ME}$ \\
\hline 423 & gil12585296 & Phosphoglucomutase, cytoplasmic & $5 / 6$ & 66 Pisum sativum & $2.5 \mathrm{e}-22$ & $65.5 / 5.6$ & $63.3 / 5.5$ & $\mathrm{ME}$ \\
\hline 427 & gil75338403 & ATP synthase subunit $\beta$, chloroplastic & $5 / 5$ & 70 Ornithogalum longebracteatum & $2.2 \mathrm{e}-50$ & $50.9 / 5.5$ & $53.2 / 5.3$ & MT \\
\hline 429 & gil78099761 & Arginosuccinate synthase, chloroplast & $3 / 6$ & 82 Arabidopsis thaliana & $1.2 \mathrm{e}-21$ & $47.6 / 5.5$ & $46.2 / 5.4$ & ME \\
\hline 436 & gil62510584 & Rab GDP dissociation inhibitor $\beta$ & $2 / 2$ & 25 Pongo abelii & $8.8 \mathrm{e}-13$ & $49.4 / 5.7$ & $50.7 / 6.1$ & ST \\
\hline 444 & gil50400860 & Monodehydroascorbate reductase & $4 / 5$ & 48 Solanum lycopersicum & $8.9 \mathrm{e}-28$ & $43.3 / 5.4$ & $47.0 / 5.8$ & ME \\
\hline 451 & gil8928411 & $\beta$-2-tubulin & $3 / 4$ & 41 Daucus carota & $6.7 \mathrm{e}-18$ & $52.8 / 4.9$ & $49.6 / 4.8$ & $\mathrm{CS}$ \\
\hline 453 & gil129699 & Proliferating cell nuclear antigen & $1 / 1$ & 8 Glycine $\max$ & $7.3 e-03$ & $35.7 / 4.7$ & $26.1 / 4.7$ & DNA \\
\hline 469 & gil1172586 & Polyphenol oxidase A1, chloroplastic & $2 / 2$ & 21 Vicia faba & $4.0 \mathrm{e}-10$ & $70.6 / 5.7$ & $58.5 / 6.0$ & $\mathrm{SM}$ \\
\hline 472 & gil18410026 & Mevalonate diphosphate decarboxylase, putative & $1 / 1$ & 16 Arabidopsis thaliana & $5.1 \mathrm{e}-04$ & $47.7 / 6.4$ & $46.1 / 6.0$ & $\mathrm{ME}$ \\
\hline \multirow[t]{2}{*}{802} & gil12229922 & Proteasome subunit $\alpha$ type- 6 & $4 / 4$ & 47 Oryza sativa & $5.0 \mathrm{e}-26$ & $26.8 / 6.4$ & $27.6 / 6.2$ & PSP \\
\hline & \multicolumn{8}{|c|}{ ) ICS39 } \\
\hline i704 & gil2499498 & Phosphoglycerate kinase, cytosolic & $3 / 5$ & 64 Nicotiana tabacum & $7.9 \mathrm{e}-32$ & $43.9 / 6.2$ & $42.4 / 5.7$ & ME \\
\hline i706 & gil224078816 & Anthocyanidin reductase & $2 / 3$ & 25 Populus trichoca & $8.5 \mathrm{e}-08$ & $40.2 / 6.1$ & $35.4 / 7.8$ & SM \\
\hline i708 & gil3913034 & $\beta$-Amylase & $2 / 3$ & 29 Vigna unguiculata & $5.8 \mathrm{e}-08$ & $60.1 / 4.8$ & $56.2 / 4.9$ & $\mathrm{ME}$ \\
\hline i710 & gil8134568 & 5-methyltetrahydropteroyltriglutamate & $4 / 4$ & 46 Mesembryaanthemum c & $1.1 \mathrm{e}-28$ & $86.3 / 6.5$ & $84.8 / 5.9$ & $\mathrm{ME}$ \\
\hline i711 & gil85700445 & Probable mitochondrial-processing peptidase $\beta$ subunit & $4 / 6$ & 68 Arabidopsis thaliana & $2.8 \mathrm{e}-31$ & $61.5 / 6.4$ & $56.2 / 5.7$ & PSP \\
\hline
\end{tabular}

${ }^{a}$ Spot name corresponds to the protein spots tagged in Fig. 1. ${ }^{b}$ NCBI Entrez entries (http://www.ncbi.nih.gov/Entrez/). ${ }^{c}$ Identification by FASTS search. ${ }^{d}$ Number of matched peptides in the FASTS query. ${ }^{e}$ Total number of amino acid used in the query. ${ }^{\mathrm{f}}$ E-score from FASTS algorithm. ${ }^{\mathrm{g}}$ Experimental $M_{\mathrm{r}}(\mathrm{kDa})$ and $\mathrm{p} I$ calculated by analysis of the gel images with PDQuest 8.0.1 software. " $T$ Theoretical $M_{\mathrm{r}}(\mathrm{kDa})$ and $\mathrm{p} I$ computed from ExPASy $M_{\mathrm{r}} / \mathrm{p} I$ calculation tool (http://au.expasy.org/tools/pi tool.html). 'Classification of proteins based on general function (ME, metabolism and energy; PSP, protein synthesis and processing; MT, membrane transport; DS, defense and stress; SM, secondary metabolism; CS, cell structure; ST, signal transduction; DNA, DNA synthesis and processing; U, unclassified). 


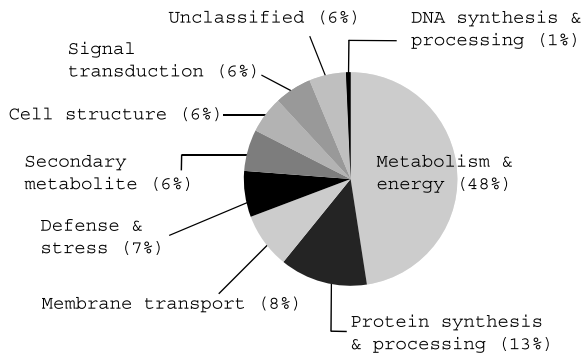

Fig. 3. Classification of proteins identified from cocoa pod husk by general functions.

tein spots were identified as leucoanthocyanidin dioxygenase (spot 173) and anthocyanidin reductase (spot i706). These two enzymes participate in the synthesis of flavan3-ol, a monomer required for formation of condensed tannin polymers (proanthocyanidins). ${ }^{45}$ This finding is consistent with an earlier report that pod husk contains condensed tannins. Moreover, two key enzymes related to lignin biosynthesis, cinnamyl alcohol dehydrogenase (spot 177) and polyphenol oxidase (spot 469) were identified. Enzymes related to lignin biosynthesis particularly interest us because their expression levels may help to explain the differences in lignification in pods with thick/hard or thin/soft sclerotic layers. As mentioned previously, pods with thick/hard (more lignified) sclerotic layers are more tolerant to CPB than pods with thin/soft sclerotic layers. Polyphenol oxidase is also believed to have a role in resistance to insects. Cotton bollworms feeding on transgenic tomato lines over-expressing polyphenol oxidase exhibit lower weight gains and foliar consumption than insects feeding on normal plants. ${ }^{46}$

Fruit development requires two major cellular activities: cell division and cell enlargement. ${ }^{47)}$ A number of identified proteins categorized in cell structure, signal transduction, and membrane transport could be linked to these processes. Four $(180,181,256,285)$ and three $(31,322$, 451) spots were identified as actin and tubulin, respectively. These are the fundamental components of the cytoskeleton. Spot 256 (actin) was exceptionally highly expressed, and is probably required for cellular processes such as cytoplasmic streaming, cell shape determination, and organelle movement. ${ }^{48)}$ Spot 139 , identified as annexin, was also abundantly expressed. Plant annexins are ubiquitous, soluble proteins capable of $\mathrm{Ca}^{2+}$-dependent and $\mathrm{Ca}^{2+}$-independent binding to endomembranes and the plasma membrane. ${ }^{49)}$ These multifunctional proteins have been reported to be involved in the Golgi-mediated secretion of wall polysaccharides in plant cells, suggesting their roles in regulation of cell wall extension. ${ }^{50)}$ In developing tomato, annexin expression is well correlated with cell expansion. ${ }^{38)}$

Cells also expand as a result of water intake into the vacuole during fruit development. ${ }^{51}$ Vacuolar ATPase (VATPase) is a multimeric enzyme that contributes to the generation of proton gradients across the tonoplast for transporting substances into the vacuole against their concentration gradient. ${ }^{38,51)}$ In tomato, V-ATPase expression is enhanced during the cell enlargement phase. ${ }^{38)}$ Suppression of V-ATPase in antisense-trangenic tomato results in reduced fruit growth. ${ }^{51)}$ In this study, we have identified two protein spots as V-ATPase (spots 265, 410).

14-3-3 proteins were identified in six spots $(372,374$, $376,377,378,385)$. These proteins are ubiquitous in plants and are major regulators of plant primary metabolism and other cellular processes. For example, members of this protein family were reported to have critical roles in regulating cotton fiber elongation ${ }^{52)}$ and starch biosynthesis in plastids. ${ }^{53)}$ In tomato, it was reported that $14-3-3$ homolog protein profiles vary with the ripening stage in fruit development, suggesting their involvement in the regulatory control of tomato fruit development. ${ }^{54}$ The many isoforms that we identified, especially the most abundant spot 385 , demonstrate their importance in pod husk development.

Several proteins associated with stress and defense, DNA synthesis, or having unclassified function were identified as well. For instance, five spots representing proteasomes were identified $(135,224,227,362,802)$. Proteasomes are known to degrade proteins, but they are also involved in various plant biological processes such as development and stress responses. In Arabidopsis thaliana mutants with a decrease in $26 \mathrm{~S}$ proteasome biogenesis, cell expansion increases, whereas complete loss of $26 \mathrm{~S}$ proteasome enhances the cellular capacity to degrade oxidized proteins. ${ }^{55)}$ Intriguingly, two protein spots $(93,413)$ were identified as $\alpha$-S1-casein. The function of this protein in pod husk is unknown.

Finally, a number of protein spots identified in this study were found to be differentially expressed between the two clones. For example, spots i704, i706, i708, i710 and 1711 were unique for the clone ICS39, whereas spots 255 and 469 were more expressed in LAFI7. These two clones differ in pod shape, surface texture, and especially in the thickness and hardness of the sclerotic layer. Clone LAFI7 has a smoother and more waxy pod surface and has a much harder and thicker sclerotic layer-features characteristic of highly CPB-resistant clones. Spots 255 and 469 were identified as caffeic acid 3-Omethyltransferase and polyphenol oxidase, respectively, enzymes involved in lignin synthesis. Thus these two enzymes may be associated with formation of the sclerotic layer. However, differential analysis between these two clones is beyond the scope of this article. Work on differential proteomic analysis between the two clones throughout pod development is currently in progress in our lab.

As conclusions, we have established a method to extract good quality proteins from cocoa pod husk that gives well-resolved 2-DE images. Protein extraction is compatible with MALDI-TOF/TOF MS and suitable for cocoa proteomic analysis. We have identified 144 protein spots from cocoa pod husk for the first time, with many associated with pod growth and development. This study can serve as a reference for future proteomic studies of cocoa tissues.

Cocoa genome sequencing is currently in progress and scheduled to be completed in 2013. Its completion will open a new era in cocoa molecular studies, including proteomics. Because the protein sequences we discovered in this study were derived independently of any database, they could be useful for validating genes after completion of genome sequencing. 
We are grateful to Dr. Douglas Furtek (Malaysian Cocoa Board) for critically reading this manuscript, to Dr. Hiroki Kuyama (Osaka University) for his valuable suggestions, and to Dr. Masayuki Taniguchi for the Bruker Autoflex III TOF/TOF-NN. We also thank Sabah Department of Agriculture, Malaysia and Mr. Haya Ramba (Malaysian Cocoa Board) and his breeding team for cocoa pods. This project was financially supported by Ministry of Science, Technology and the Innovation, Malaysia (e-Science project No. 02-03-13-SF0011) and Nara Institute Science and Technology, Supported by The Ministry of Education, Culture, Sports, Science and Technology, Japan (Scientific Research for Plant Graduate Students).

\section{REFERENCES}

1 ) I. Azhar: Studies on sclerotic layer hardness of cocoa pods. MARDI Res. J., 18, 63-69 (1990).

2 ) D. Santoso, T. Chaidamsari, S. Wiryadiputra and R. A de Maagd: Activity of Bacillus thuringiensis toxins against cocoa pod borer larvae. Pest Manag. Sci., 60, 735-738 (2004).

3 ) I. Azhar, G.E. Long and M.J. Musa: Qualitative and multivariate analyses of clonal cocoa resistance to cocoa pod borer (Lepidoptera: Gracillaridae). Planter, 71, 307-321 (1995).

4 ) L.H. Shapiro, S.J. Scheffer, N. Maisin, S. Lambert, H.B. Purung, E. Sulistyowati, F.E. Vega, P. Gende, S. Laup, A. Rosmana, S. Djam and P.K. Hebbar: Conopomorpha cramerella (Lepidoptera: Gracillariidae) in the Malay archipelago: genetic signature of a bottlenecked population. Ann. Entomol. Soc. Am., 101, 930-938 (2008)

5 ) Misnawi and W. Teguh: Potential uses of cocoa bean infested by Conopomorpha cramerella for polyphenol extraction. ASEAN Food J., 15, 27-34 (2008).

6 ) A. Zhang, L.F. Kuang, N. Maisin, B. Karumuru, D.R. Hall, I. Virdiana, S. Lambert, H.B. Purung, S. Wang and P. Hebbar: Activity evaluation of cocoa pod borer sex pheromone in cacao fields. Environ. Entomol., 37, 719-724 (2008).

7 ) I. Azhar and D.H.K. Lim: An investigation on the use of host plant resistance and crop manipulation in the management of cocoa pod borer. in Management of the Cocoa Pod Borer, P. A.C. Ooi, G.C. Luz, K.C. Khoo, C.H. Teoh, M.M. Jusoh, C.T. Ho and G.S. Lim, eds., Malaysian Plant Protection Society, Kuala Lumpur, pp. 83-101 (1987).

8 ) I. Azhar and G.E. Long: Effect of cocoa and pod age on egg distribution and egg parasitism of the cocoa pod borer in Malaysia. Entomol. Exp. Appl., 81, 81-89 (1996).

9 ) A. Dove: Proteomics: translating genomics into products? Nat. Biotechnol., 17, 233-236 (1999).

10) J.V. Jorrin-Novo, A.M. Maldono, S. Echevarria-Zomeno, L. Valledor, M.A. Castillejo, M. Curto, J. Valero, B. Sghaier, G. Donoso and I. Redondo: Plant proteomics update (2007-2008): second-generation proteomic techniques, an appropriate experimental design, and data analysis to fulfill MIAPE standards, increase plant proteome coverage and expand biological knowledge. J. Proteomics, 72, 285-314 (2009).

11) G.H. Salekdeh and S. Komatsu: Crop proteomics: aim at sustainable agriculture of tomorrow. Proteomics, 7, 2976-2996 (2007).

12) S. Beranova-Giorgianni: Proteome analysis by two-dimensional gel electrophoresis and mass spectrometry: strengths and limitations. Trends Anal. Chem., 22, 273-281 (2003).

13) W. Weiss and A. Gorg: High resolution two-dimensional electrophoresis. in Proteomics: Methods and Protocols, J. Reinders and A. Sickmann, eds., Humana Press, New York, pp. 13-32 (2009).

14) S.C. Carpentier, E. Witters, K. Laukens, P. Deckers, R. Swennen and B. Panis: Preparation of protein extracts from recalcitrant plant tissues: an evaluation of different methods for twodimensional gel electrophoresis analysis. Proteomics, 5, 24972507 (2005)

15) S.C. Carpentier, B. Panis, A. Vertommen, R. Swennen, K. Sergeant, J. Renaut, K. Laukens, E. Witters, B. Samyn and B. Devreese: Proteome analysis of non-model plants: a challenging but powerful approach. Mass Spectrom. Rev., 27, 354-377
(2008).

16) D.L. Zak and P.G. Keeney: Changes in cocoa proteins during ripening of fruit, fermentation, and further processing of cocoa beans. J. Agric. Food Chem., 24, 483-486 (1976).

17) E. Lerceteau, J. Rogers, V. Pétiard and D. Crouzillat: Evolution of cacao bean proteins during fermentation: a study by two-dimensional electrophoresis. J. Sci. Food Agric., 79, 619625 (1999).

18) C.P. Pirovani, H.A.S. Carvalho, R.C.R. Machado, D.S. Gomes, F.C. Alvim, A.W.V. Pomella, K.P. Gramacho, J.C.D.M. Cascardo, G.A.G. Pereira and F. Micheli: Protein extraction for proteome analysis from cacao leaves and meristems, organs infected by Moniliophthora perniciosa, the causal agent of the witches' broom disease. Electrophoresis, 29, 2391-2401 (2008).

19) A. Figuera, J. Janick and J.N. BeMiller: Partial characterization of cacao pod and stem gums. Carbohydr. Polym., 24, 133-138 (1994).

20) A.D.S. Gesteira, F. Micheli, C.F. Ferreira and J.C.D.M. Cascardo: Isolation and purification of functional total RNA from different organs of cacao tree during its interaction with the pathogen Crinipellis perniciosa. Biotechniques, 35, 494-500 (2003).

21) N.A. Adamafio, I.K. Afeke, J. Wepeba, E.K. Ali and F.O. Quaye: Biochemical composition and in vitro digestibility of cocoa (Theobroma cacao) pod husk, cassava (Manihot esculenta) peel and plantain (Musa Paradisiaca) peel. Ghana J. Sci., 44, 29-38 (2004).

22) W. Wang, M. Scali, R. Vignani, A. Spadafora, E. Sensi, S. Mazzuca and M. Cresti: Protein extraction for two-dimensional electrophoresis from olive leaf, a plant tissue containing high levels of interfering compounds. Electrophoresis, 24, 23692375 (2003).

23) B. Samyn, K. Sergeant, S. Memmi, G. Debyser, B. Devreese and J. Van Beeumen: MALDI-TOF/TOF de novo sequence analysis of 2-D PAGE-separated proteins from Halorhodospira halophila, a bacterium with unsequenced genome. Electrophoresis, 27, 2702-2711 (2006).

24) B. Samyn, K. Sergeant, S. Carpentier, G. Debyser, B. Panis, R. Swennen and J. Van Beeumen: Functional proteome analysis of the banana plant (Musa spp.) using de novo sequence analysis of derivatized peptides. J. Proteome Res., 6, 70-80 (2007).

25) X. Zhang, A. Rogowska-Wrzesinska and P. Roepstorff: Ontarget sample preparation of 4-sulfophenyl isothiocyanatederivatized peptides using AnchorChip Targets. J. Mass Spectrom., 43, 346-359 (2008).

26) I.R. León, A.G.C. Neves-Ferreira, R.H. Valente, E.M. Mota, H.L. Lenzi and J. Perales: Improved protein identification efficiency by mass spectrometry using N-terminal chemical derivatization of peptides from Angiostrongylus costaricensis, a nematode with unknown genome. J. Mass Spectrom., 42, 781792 (2007).

27) V. Neuhoff, N. Aron, D. Taube and W. Ehrhardt: Improved staining of proteins in polyacrylamide gels including isoelectric focusing gels with clear background at nanogram sensitivity using Coomasie Brilliant Blue G-250 and R-250. Electrophoresis, 9, 255-262 (1998).

28) D. Wang, S.R. Kalb and R.J. Cotter: Improved procedures for $\mathrm{N}$-terminal sulfonation of peptides for matrix-assisted laser desorption/ionization post-source decay peptide sequencing. Rapid Commun. Mass Spectrom., 18, 96-102 (2004).

29) A.J. Mackey, T.A.J. Haystead and W.R. Pearson: Getting more from less: algorithms for rapid protein identification with multiple short peptide sequences. Mol. Cell. Proteomics, 1, 139147 (2002).

30) A. Shevchenko, S. Sunyaev, A. Loboda, A. Shevchenko, P. Bork, W. Ens and K.G. Standing: Charting the proteomes of organisms with unsequenced genomes by MALDI-quadrupole time-of-flight mass spectrometry and BLAST homology searching. Anal. Chem., 73, 1917-1926 (2001).

31) D. Adomako: Cocoa pod husk pectin. Phytochemistry, 11, 1145-1148 (1972).

32) Y. Yao, Y.-W. Yang and J.-Y. Liu: An efficient protein prepa- 
ration for proteomic analysis of developing cotton fibers by 2DE. Electrophoresis, 27, 4559-4569 (2006).

33) S. Gómez-Vidal, M. Tena, L.V. Lopez-Llorca and J. Salinas: Protein extraction from Phoenix dactylifera L. leaves, a recalcitrant material, for two-dimensional electrophoresis. Electrophoresis, 29, 448-456 (2008).

34) S.C. Carpentier, K. Dens, I. Van den Houwe, R. Swennen and B. Panis: Lyophilization, a practical way to store and transport tissues prior to protein extraction for $2 \mathrm{DE}$ analysis? Proteomics, 7, S64-S69 (2007).

35) C. Hughes, B. Ma and G.A. Lajoie: De novo sequencing methods in proteomics. in Proteome Bioinformatics, S.J. Hubbard and A.R. Jones, eds., Humana Press, New York, pp. 105121 (2009).

36) J. Franck, M. El Ayed, M. Wisztorski, M. Salzet and I. Fournier: On-tissue N-terminal peptide derivatizations for enhancing protein identification in MALDI mass spectrometric imaging strategies. Anal. Chem., 81, 8305-8317 (2009).

37) N. Imin, F. De Jong, U. Mathesius, G. Van Noorden, N.A. Saeed, X.-D. Wang, R.J. Rose and B.G. Rolfe: Proteome reference maps of Medicago truncatula embryogenic cell cultures generated from single protoplasts. Proteomics, 4, 1883-1896 (2004).

38) M. Faurobert, C. Mihr, N. Bertin, T. Pawlowski, L. Negroni, N. Sommerer and M. Causse: Major proteome variations associated with cherry tomato pericarp development and ripening. Plant Physiol., 143, 1327-1346 (2007).

39) A.I. Baba, F.C.S. Nogueira, C.B. Pinheiro, J.N. Brasil, E.S. Jereissati, T.L. Jucá, A.A. Soares, M.F. Santos, G.B. Domont and F.A.P. Campos: Proteome analysis of secondary somatic embryogenesis in cassava (Manihot esculenta). Plant Sci., 175, 717-723 (2008).

40) D.I. Jacobs, M. Gaspari, J. van der Greef, R. van der Heijden and R. Verpoorte: Proteome analysis of the medical plant $\mathrm{Ca}$ tharantus roseus. Planta, 221, 690-704 (2005).

41) F. Van Breusegem, R. Dekeyser, J. Gielen, M. Van Montagu and A. Caplan: Characterization of a S-Adenosylmethionine synthetase gene in rice. Plant Physiol., 105, 1463-1464 (1994).

42) R.A. Saftner and B.G. Baldi: Polyamine levels and tomato fruit development: possible interaction with ethylene. Plant Physiol., 92, 547-550 (1990).

43) J. Grimplet, M.D. Wheatley, H. Ben Jouira, L.G. Deluc, G.R. Cramer and J.C. Cushman: Proteomic and selected metabolite analysis of grape berry tissues under well-watered and waterdeficit stress conditions. Proteomics, 9, 2503-2528 (2009).

44) M.J. Mayer, A. Narbad, A.J. Parr, M.L. Parker, N.J. Walton, F.A. Mellon and A.J. Michael: Rerouting the plant phenylpropanoid pathway by expression of a novel bacterial enoyl-CoA hydratase/lyase enzyme function. Plant Cell, 13, 1669-1682 (2001).

45) J. Bogs, M.O. Downey, J.S. Harvey, A.R. Ashton, G.J. Tanner and S.P. Robinson: Proanthocyanidin synthesis and expression of genes encoding leucoanthocyanidin reductase and anthocyanidin reductase in developing grape berries and grapevine leaves. Plant Physiol., 139, 652-663 (2005).

46) A. Bhonwong, M.J. Stout, J. Attajarusit and P. Tantasawat: Defensive role of tomato polyphenol oxidases against cotton bollworm (Helicoverpa armigera) and beet armyworm (Spodoptera exigua). J. Chem. Ecol., 35, 28-38 (2009).

47) S.E. Ledger and R.C. Gardner: Cloning and characterization of five cDNAs for genes differentially expressed during fruit development of kiwifruit (Actinidia deliciosa var. deliciosa). Plant Mol. Biol., 25, 877-886 (1994).

$48)$ K. Gallardo, C. Le Signor, J. Vandekerckhove, R.D. Thompson and J. Burstin: Proteomics of Medicago truncatula seed development establishes the time frame of diverse metabolic processes related to reserve accumulation. Plant Physiol., 133, 664-682 (2003).
49) J.C. Mortimer, A. Laohavisit, N. Macpherson, A. Webb, C. Brownlee, N.H. Battey and J.M. Davies: Annexins: multifunctional components of growth and adaptation. J. Exp. Bot., 59, 533-544 (2008).

50) J. Proust, G. Houlne, M.-L. Schantz and R. Schantz: Characterization and gene expression of an annexin during fruit development in Capsicum annuит. FEBS Lett., 383, 208-212 (1996).

51) T. Amemiya, Y. Kanayama, S. Yamaki, K. Yamada and K. Shiratake: Fruit-specific V-ATPase suppression in antisensetransgenic tomato reduces fruit growth and seed formation. Planta, 223, 1272-1280 (2006).

52) P.-M. Zhao, L.-L. Wang, L.-B. Han, J. Wang, Y. Yao, H.-Y. Wang, X.-M. Du, Y.-M. Luo and G.-X. Xia: Proteomic identification of differentially expressed proteins in the Ligon lintless mutant of upland cotton (Gossypium hirsutum L.). J. Proteome Res., 9, 1076-1087 (2010).

53) P.C. Sehnke, H.-J. Chung, K. Wu and R.J. Ferl: Regulation of starch accumulation by granule-associated plant $14-3-3$ proteins. Proc. Natl. Acad. Sci. U.S.A., 98, 765-770 (2001).

54) B. Laughner, S.D. Lawrence and R.J. Ferl: Two cDNA clones encoding 14-3-3 homologs from tomato fruit. Biochim. Biophys. Acta, 1263, 67-70 (1995).

55) J. Kurepa, S. Wang, Y. Li, D. Zaitlin, A.J. Pierce and J.A. Smalle: Loss of $26 \mathrm{~S}$ proteasome function leads to increased cell size and decreased cell number in Arabidopsis shoot organs. Plant Physiol., 150, 178-189 (2009).

\section{カカオポッド果殼のプロテオミック解析}

$$
\begin{aligned}
& \text { アズワン アワング1,2, ラフィアカリム }{ }^{2} \text {, 三ツ井敏明 }{ }^{1} \\
& 1 \text { 新潟大学大学院自然科学研究科生命· } \\
& \text { 食料科学専攻植物・微生物ゲノムコントロール大講座 } \\
& \text { (950-2181 新潟市西区五十嵐 } 2 \text { の町 8050) } \\
& 2 \text { マレーシアココア局 }
\end{aligned}
$$

(Locked Bag 211, 88999 Kota Kinabalu, Sabah, Malaysia)

カカオ (Theobroma cacao) は, 多くの熱帯地域の国の 重要な作物であり, チョコレートの原材料として栽培さ れている。 カカオにおいても害虫耐性の付与など品種改 良が望まれているが, その基礎となるカカオの生理・生 化学, 分子遺伝学についてはほとんどわかっていない. また, 現時点ではカカオのゲノム情報も明らかにされて いない. われわれは, カカオポッド果殼のプロテオーム を明らかにするため 2 次元電気泳動 (2-DE)/質量分析を 行った。カカオポッドには大量のガムが含まれているた め, ポッド果殼タンパク質をフェノール抽出／メタノー ル-酢酸アンモニア沈澱法により調製した.タンパク質試 料を2-DEで分離し，コロイド CBBで染色したところ， 2-DE ゲル中において約 700 のタンパクスポットを検出す ることができた。 244 個のタンパクスポットについてトリ プシン消化物のSPITC-誘導体を調製し, MALDI-TOF/ TOF MS を用いた de novo シークエンシングを行った。こ の方法により 144 個のカカオポッド果殼タンパク質を同 定することができた。同定されたタンパク質の大部分は 代謝やエネルギー生産に関与するものであった。また， ポッドの成長・分化に関わるタンパク質も検出された. 
Supplementary Table 1(a). De novo derived peptide sequences for the identification of proteins from cocoa clone LAFI7.

\begin{tabular}{|c|c|c|c|c|c|c|}
\hline Spot & $\begin{array}{c}\text { Accession } \\
\text { number }\end{array}$ & Protein & $\begin{array}{l}\text { Precursor } \\
\text { ion }\end{array}$ & Sequence & E-score & $\begin{array}{c}\text { MS-Blast } \\
\text { score }\end{array}$ \\
\hline 6 & & - & 1315.646 & SXXXLVVTDWR & & \\
\hline \multirow{2}{*}{10} & & - & 950.636 & GYTPLFPR & & \\
\hline & & & 1399.705 & LKGLGLR & & \\
\hline \multirow[t]{3}{*}{11} & gil113363 & Alcohol dehydrogenase 1 & 950.624 & GYTPLFPR & $4.7 e-03$ & 170 \\
\hline & & & 1010.652 & LLAVDLNPR & & \\
\hline & & & 1398.710 & YFLQGLGLR & & \\
\hline \multirow[t]{2}{*}{15} & gil2494175 & Glutamate decarboxylase 2 & 1345.590 & NLLENCLENAR & $7.8 \mathrm{e}-06$ & 118 \\
\hline & & & 1673.970 & GXXXLLAQYYKXXR & & \\
\hline \multirow[t]{3}{*}{16} & gil6015065 & - & 744.207 & FFAFGR & & \\
\hline & & & 969.447 & GXXLLPTAR & & \\
\hline & & & 1788.901 & AXXPVLEFSSSXXPLR & & \\
\hline 17 & gil6015065 & Elongation factor 2 & 1786.874 & AYLPVLESFGFSSTLR & $3.5 \mathrm{e}-09$ & 111 \\
\hline \multirow{7}{*}{18} & gil8134568 & 5-methyltetrahydropteroyltriglutamate & 734.278 & LLWFR & $3.3 \mathrm{e}-42$ & 421 \\
\hline & & & 902.389 & WAVHSFR & & \\
\hline & & & 1096.701 & YLFAGVVDGR & & \\
\hline & & & 1149.667 & GVTAYGVDLVR & & \\
\hline & & & 1482.817 & AXXNVLKLDEAALR & & \\
\hline & & & 1540.679 & DEAFFSANAAALASR & & \\
\hline & & & 1658.804 & YQXXGPGVYDLHSR & & \\
\hline \multirow[t]{2}{*}{21} & & - & 1241.668 & FXXFSGCKLR & & \\
\hline & & & 1950.030 & $\mathrm{HR}$ & & \\
\hline \multirow[t]{2}{*}{24} & & - & 1443.661 & ADXXEEALNLVNR & & \\
\hline & & & 1530.695 & YXXKSVFTTTSGAAAR & & \\
\hline 25 & gil3914360 & Phospholipase $\mathrm{D} \alpha 1$ & 1543.619 & HDAHER & $4.6 \mathrm{e}-05$ & 67 \\
\hline & & & 1571.767 & FXXXXTFYSQR & & \\
\hline & & & 2188.298 & FXXKDDNXXGATXXXR & & \\
\hline 27 & & - & 1200.710 & VXXSVSNPDTR & & \\
\hline 31 & gil51701894 & Tubulin $\beta-1$ chain & 1342.623 & LNVYYNEASNR & $9.9 \mathrm{e}-04$ & 68 \\
\hline 34 & & - & 1061.547 & FXXLPFTAR & & \\
\hline & & & 1697.949 & VAAVNTAAEVAL & & \\
\hline 35 & gil3914449 & Protease regulatory subunit 7 & 1132.671 & DXXFELLAR & $9.3 e-34$ & 250 \\
\hline & & & 1389.818 & KXXFXXAXXLESR & & \\
\hline & & & 1407.553 & FDDGVGGDNEVKR & & \\
\hline & & & 1721.947 & LVNQLDGFDAR & & \\
\hline & & & 1740.894 & FFDEVDALGGAR & & \\
\hline 42 & & - & 888.509 & VXXLDVLR & & \\
\hline & & & 952.056 & DXXSLVXXR & & \\
\hline 46 & & - & 1298.512 & YXXFYLLHR & & \\
\hline & & & 1513.634 & YQPXXGGFGVXXR & & \\
\hline 48 & gil2499489 & Pyrophosphate-fructose 6-phosphate 1-phosphotransferase subunit & 912.476 & GXXLYGFR & $6.3 e-15$ & 175 \\
\hline & & & 1284.396 & GQSHFFGYEGR & & \\
\hline & & & 1665.604 & YXXNTADYLYXXR & & \\
\hline 49 & gil10720307 & T-complex protein 1 subunit $\xi$ & 1732.699 & SXXNAGFFYSNAEQR & $8.1 \mathrm{e}-08$ & 199 \\
\hline & & & 2033.069 & DEAVVLGAGAFEVAAR & & \\
\hline 50 & gil6225542 & Ketol-acid reductoisomerase, chloroplastic & 1544.638 & MVDNCSTTAR & $7.1 \mathrm{e}-20$ & 249 \\
\hline & & & 1629.800 & EXXSLAGHDEYLVR & & \\
\hline & & & 2073.686 & ELDKGLNSSFGVHQDVDR & & \\
\hline 51 & & - & 1680.920 & FXXSESWLKVEGR & & \\
\hline & & & 1851.909 & LSHDXXAXXR & & \\
\hline 53 & gil2501356 & Transketolase, chloroplastic & 996.376 & NPYWFNR & $6.2 \mathrm{e}-13$ & 149 \\
\hline & & & 1615.648 & ALXXYTPESPPDATR & & \\
\hline 57 & gil2501356 & Transketolase, chloroplastic & 996.444 & NXXWFNR & $1.3 \mathrm{e}-12$ & 146 \\
\hline & & & 1615.745 & ALPTYTPESPPDATR & & \\
\hline 58 & & - & 996.384 & NPYWFNR & & \\
\hline 60 & gil2499489 & Pyrophosphate-fructose 6-phosphate 1-phosphotransferase subunit & 884.394 & YYHFVR & $9.1 \mathrm{e}-10$ & 124 \\
\hline & & & 1284.431 & GXXHFFGYEGR & & \\
\hline & & & 1639.671 & VLWD & & \\
\hline & & & 1672.734 & TXXVGFGLVLWDXXR & & \\
\hline 61 & gil2499489 & Pyrophosphate-fructose 6-phosphate 1-phosphotransferase subunit & 884.394 & YYHFVR & $6.1 \mathrm{e}-35$ & 337 \\
\hline & & & 912.452 & GXXLYGFR & & \\
\hline & & & 1284.511 & GKSHFFGYEGR & & \\
\hline & & & 1486.055 & EVXXSFGFDTACR & & \\
\hline & & & 1665.594 & YVELTADYLYPYR & & \\
\hline 62 & gil25452981 & Glucose-6-phosphate-dehydrogenase & 986.440 & GDQKHFVR & $1.8 \mathrm{e}-24$ & 207 \\
\hline & & & 1058.625 & LFLPLWNR & & \\
\hline & & & 1289.575 & GXXFDEYGLLR & & \\
\hline & & & 1890.802 & YVSGSYDAAEGFQLLDR & & \\
\hline 63 & & - & 922.511 & LFNLYPR & & \\
\hline & & & 942.456 & AFGLDDFR & & \\
\hline & & & 1133.498 & SLQAXXR & & \\
\hline & & & 1300.471 & NKFCDAGLGYR & & \\
\hline 64 & gil54038948 & Phosphoribosylaminoimidazolecarboxamide formyltransferase & 1254.598 & YRSLVFTNVR & $6.4 \mathrm{e}-07$ & 131 \\
\hline & & & 1398.826 & TLHPNLHGGLLAR & & \\
\hline 65 & gil6225542 & ketol-acid reductoisomerase chloroplastic & 2073.885 & ELDKGLNSSFGVHKDVDGR & $5.0 \mathrm{e}-06$ & 96 \\
\hline 67 & gil135535 & T-complex protein $1 \alpha$ subunit & 1195.561 & YFVEAGALAVR & $3.5 \mathrm{e}-13$ & 148 \\
\hline & & & 1571.782 & EXXLLDGYALNTGR & & \\
\hline
\end{tabular}




\begin{tabular}{|c|c|c|c|c|c|c|}
\hline Spot & $\begin{array}{l}\text { Accession } \\
\text { number }\end{array}$ & Protein & $\begin{array}{l}\text { Precursor } \\
\text { ion }\end{array}$ & Sequence & E-score & $\begin{array}{l}\text { MS-Blast } \\
\text { score }\end{array}$ \\
\hline & & & 1874.799 & EWSLLLLDNXXXR & & \\
\hline \multirow[t]{3}{*}{68} & gil146286092 & Coatomer subunit $\delta$ & 912.391 & GAELYXXR & $7.4 \mathrm{e}-06$ & 85 \\
\hline & & & 1665.488 & TADYLYXXR & & \\
\hline & & & 1875.784 & EWSLLLLDNSNR & & \\
\hline \multirow[t]{4}{*}{69} & gil3914394 & 2,3-biphosphoglycerate-independent phosphoglycerate mutase & 1346.567 & TXXYLVHDAVR & $7.1 \mathrm{e}-26$ & 278 \\
\hline & & & 1346.567 & LXXLSGQFDQVR & & \\
\hline & & & 1547.650 & AXXYEDFDKFDR & & \\
\hline & & & 1776.783 & AVGXXVDGDAVVTFNFR & & \\
\hline \multirow[t]{3}{*}{70} & gil75115272 & ketol-acid reductoisomerase & 1560.652 & FVDNCSTTAR & $9.3 e-21$ & 237 \\
\hline & & & 1980.746 & KLRLGWGSKGPAKAKNLR & & \\
\hline & & & 2088.084 & ELDKGLNSSFAVHKDVDGR & & \\
\hline \multirow[t]{3}{*}{71} & gil543865 & ATP synthase subunit $\alpha$, mitochondria & 1077.635 & EDAVGNLFGR & $2.8 \mathrm{e}-13$ & 185 \\
\hline & & & 1537.864 & EXXPGDVFYLHSR & & \\
\hline & & & 1816.878 & TNFQVDELGR & & \\
\hline \multirow[t]{4}{*}{72} & gil266346 & ketol-acid reductoisomerase & 823.332 & SDLFWR & $4.8 \mathrm{e}-10$ & 188 \\
\hline & & & 1449.545 & ADLXXLFDTDVDR & & \\
\hline & & & 1559.536 & VDNCSTTAR & & \\
\hline & & & 2086.445 & ELDQGLNSSFAVHQDVDR & & \\
\hline \multirow[t]{2}{*}{73} & & - & 1087.501 & GXXAQLASGNR & & \\
\hline & & & 1347.426 & LVHDXXR & & \\
\hline 74 & gil74996549 & T-complex protein 1 subunit $\beta$ & 1173.458 & VDELLTCAPR & $2.5 \mathrm{e}-03$ & 146 \\
\hline & & & 1320.560 & GXXHHVLDEAER & & \\
\hline & & & 1531.545 & CXXXDLTRPXXR & & \\
\hline 75 & & - & 776.405 & VXXLQR & & \\
\hline 76 & gil1172858 & Ribulose-1,5-biphosphate carboxylase large chain & 1021.642 & DTDLLAAFR & $8.4 \mathrm{e}-30$ & 276 \\
\hline & & & 1116.572 & VALEACVQAR & & \\
\hline & & & 1187.564 & DNXXLLHLHR & & \\
\hline & & & 1465.694 & TFQGPPHGLKVER & & \\
\hline 77 & gil14423687 & Enolase 2 & 806.424 & YNQLLR & $5.6 \mathrm{e}-16$ & 158 \\
\hline & & & 1491.453 & LGAAAVYXXR & & \\
\hline & & & 1795.543 & AXXXXKSTSTYEALELR & & \\
\hline & & & 1801.796 & GNXXVEADVTLSDGTVAR & & \\
\hline 81 & gil543865 & ATP synthase subunit $\alpha$ & 815.427 & ELLLGDR & $1.6 \mathrm{e}-58$ & 546 \\
\hline & & & 859.954 & KMSLLLR & & \\
\hline & & & 892.448 & LELAQYR & & \\
\hline & & & 972.418 & VVSVGDGLAR & & \\
\hline & & & 1026.440 & AVDSLVPLGR & & \\
\hline & & & 1210.481 & VVDALGVPLDGR & & \\
\hline & & & 1537.525 & EAFPGDVFYLHSR & & \\
\hline & & & 1816.705 & LTNFYTNFQVDELR & & \\
\hline 84 & & - & 1071.463 & LXXKPQTDR & & \\
\hline & & & 1271.496 & GLTFDSGGYXXR & & \\
\hline & & & 1318.429 & VNNESAEGR & & \\
\hline & & & 1427.514 & YAEDVSSALLFGR & & \\
\hline & & & 1617.631 & ATLGLTQPANLEHPR & & \\
\hline & & & 1684.752 & VXXLGLGQSVLSPAAFR & & \\
\hline & & & 1757.585 & GQXXQEYWWCTER & & \\
\hline & & & 1873.740 & WVFPDTNSGLLVLAEGR & & \\
\hline & & & 2023.789 & LXXASALASGTVLRYEDNR & & \\
\hline & & & 2189.190 & FSTQDHAAS & & \\
\hline 86 & gil6094242 & Putative selenium-binding protein & 1546.585 & GFNLQHVADGLYGR & $1.0 \mathrm{e}-22$ & 294 \\
\hline & & & 1624.607 & TWKCNVXXLQGHR & & \\
\hline & & & 1702.618 & EXXLYVTCVYTGTGR & & \\
\hline & & & 1739.703 & KTLDLGDSGLLPLELR & & \\
\hline 87 & gil543865 & ATP synthase subunit $\alpha$, mitochondrial & 1179.449 & YEELQLTAQR & $1.1 \mathrm{e}-12$ & 98 \\
\hline & & & 1537.436 & VFYLHSR & & \\
\hline & & & 1815.575 & LXXFYTNFQVDELGR & & \\
\hline & & & 1871.429 & WVFXXTNSXXLVLAEGR & & \\
\hline 88 & gil14423687 & Enolase 2 & 806.384 & YNQLLR & $2.6 \mathrm{e}-19$ & 224 \\
\hline & & & 1071.367 & GVMASHR & & \\
\hline & & & 1087.350 & AXXGVFASHR & & \\
\hline & & & 1797.619 & LEEELGADAVYAGASFR & & \\
\hline & & & 1797.619 & QSTRYEALELR & & \\
\hline 91 & & - & 1036.479 & SLAKEYGLR & & \\
\hline & & & 1649.621 & FXXXXQPXXDYQKR & & \\
\hline & & & 1717.724 & FXXLSTVHYLSGXXR & & \\
\hline 92 & gil25453205 & Peroxidase 12 & 1013.665 & DLGQAAGLLR & $8.6 e-19$ & 330 \\
\hline & & & 1262.551 & ATAFELLDNLR & & \\
\hline & & & 1374.760 & VVSCSDLLALAAR & & \\
\hline & & & 1745.773 & KXXFTSDQDLYTDSR & & \\
\hline & & & 1809.869 & DWYLSGGPDYDVPLR & & \\
\hline 93 & gil115646 & $\alpha$-S1-casein & 830.478 & AVPYPQR & $4.5 \mathrm{e}-20$ & 131 \\
\hline & & & 875.307 & FASPLAR & & \\
\hline & & & 1104.623 & YLGYLEQLLR & & \\
\hline & & & 1337.597 & HLKQEDVPSER & & \\
\hline & & & 1696.902 & DYVDLPHS & & \\
\hline & & & 1759.880 & HQXXXXEVLNE & & \\
\hline 94 & gil12585489 & UDP-glucose pyrophosphorylase & 1312.563 & VLQLETAAGAALR & $4.0 \mathrm{e}-35$ & 305 \\
\hline
\end{tabular}




\begin{tabular}{|c|c|c|c|c|c|c|}
\hline Spot & $\begin{array}{l}\text { Accession } \\
\text { number }\end{array}$ & Protein & $\begin{array}{l}\text { Precursor } \\
\text { ion }\end{array}$ & Sequence & E-score & $\begin{array}{l}\text { MS-Blast } \\
\text { score }\end{array}$ \\
\hline \multirow{8}{*}{95} & & & 1371.613 & FFDHALGVNVPR & & \\
\hline & & & 2197.660 & YSNSNLELHTFNQSQYPR & & \\
\hline & gil1169534 & Enolase & 806.456 & YNKLLR & $5.3 e-32$ & 301 \\
\hline & & & 1071.448 & AXXGVMASHR & & \\
\hline & & & 1719.926 & GASTGVYEALELR & & \\
\hline & & & 1791.760 & AXXPSGASTGVYEALELR & & \\
\hline & & & 1795.698 & LGADAVYAGASFR & & \\
\hline & & & 1797.618 & LEEELGADAVYAGASFR & & \\
\hline \multirow[t]{4}{*}{96} & gil400246 & $S$-adenosylmethionine synthetase I & 1141.399 & TLFHLNPSGR & $9.4 \mathrm{e}-19$ & 201 \\
\hline & & & 1453.515 & FVLGGPHGDAGLTGR & & \\
\hline & & & 1747.566 & TSDKDLYTDSR & & \\
\hline & & & 1809.309 & DADYLSGGPDYDVXXGR & & \\
\hline \multirow[t]{3}{*}{97} & gil400246 & $S$-adenosylmethionine synthetase I & 979.417 & TAAYGHFGR & $2.3 e-27$ & 240 \\
\hline & & & 1141.527 & TLFHLNPSGR & & \\
\hline & & & 1453.746 & FVLGGPHGDAGLTGR & & \\
\hline \multirow[t]{5}{*}{98} & gil400246 & $S$-adenosylmethionine synthetase I & 979.307 & TAAYGHFGR & $6.9 \mathrm{e}-25$ & 256 \\
\hline & & & 1141.470 & TXXHLNPSGR & & \\
\hline & & & 1248.418 & LXXNYEEXXR & & \\
\hline & & & 1394.154 & SXXSPLNQVQSR & & \\
\hline & & & 1453.853 & FVLGGPHGDAGLTGR & & \\
\hline \multirow[t]{6}{*}{99} & gil68052019 & Biotin carboxylase & 955.498 & LLVWAXXR & $1.3 \mathrm{e}-06$ & 281 \\
\hline & & & 1133.440 & LLLDLEDFR & & \\
\hline & & & 1177.406 & VHFWR & & \\
\hline & & & 1342.559 & LNFLGPNPDSLR & & \\
\hline & & & 1393.507 & LPSGGKXXR & & \\
\hline & & & 1634.677 & APSPALTXXLR & & \\
\hline \multirow[t]{4}{*}{100} & & - & 855.510 & LEXXATPR & & \\
\hline & & & 1393.641 & LXXMLPSGGXXVR & & \\
\hline & & & 1434.784 & DASVAYKR & & \\
\hline & & & 1897.856 & EKLYLLLSCCPCEGR & & \\
\hline 101 & & - & 830.877 & AVPGYPGAR & & \\
\hline & & & 917.590 & EVVKWTR & & \\
\hline & & & 1760.289 & VLNER & & \\
\hline & & & SPT 2417 & FLLYQEXXL & & \\
\hline 102 & gil20141399 & 3-oxoacyl-[acyl-carrier-protein] synthase & 1068.519 & FDASKFPTR & $2.7 \mathrm{e}-17$ & 204 \\
\hline & & & 1111.516 & ESXXYFAER & & \\
\hline & & & 1173.525 & LDLLLS & & \\
\hline & & & 1263.602 & ADXXGVSSCLER & & \\
\hline & & & 1297.641 & LLAGESGLGPLDR & & \\
\hline & & & 1629.821 & KSFPADLR & & \\
\hline & & & 1882.877 & TKGQHGVATATV & & \\
\hline 103 & gil73919692 & GDP-D-mannose 3,5-epimerase & 896.413 & DFGLECR & $6.9 \mathrm{e}-26$ & 286 \\
\hline & & & 1049.382 & EKAMTLNSR & & \\
\hline & & & 1045.216 & SSLYFCR & & \\
\hline & & & 1424.869 & VVGTQAPVQLGSLR & & \\
\hline & & & 1570.953 & LXXTQGGFLASHLAR & & \\
\hline & & & 1671.583 & LDECVEGVLR & & \\
\hline 105 & & - & 1219.600 & GDXXYLYTGR & & \\
\hline L106 & & - & 1250.662 & YLEPPHLLLR & & \\
\hline & & & 1273.762 & TLFCTSLLYR & & \\
\hline & & & 1380.720 & LLLKR & & \\
\hline 107 & & - & 851.476 & EHLLLAR & & \\
\hline 108 & gil189044723 & Elongation factor $\mathrm{Tu} 2$ & 1010.523 & LLAVDLNPR & $1.1 \mathrm{e}-16$ & 169 \\
\hline & & & 1681.861 & LLDQGQAGDNVGLLLR & & \\
\hline & & & 1787.949 & ATAHVEYEXXKR & & \\
\hline 110 & gil122064253 & Isocitrate dehydrogenase $[\mathrm{NAD}]$ regulatory subunit 1 & 1217.650 & HLKFPSFWR & $1.4 \mathrm{e}-12$ & 145 \\
\hline & & & 1280.601 & LWGLFLESCR & & \\
\hline & & & 1423.788 & YAFEYAYLNNR & & \\
\hline 115 & gil126896 & Malate dehydrogenase, mitochondrial & 811.406 & AXXYDER & $3.3 e-13$ & 114 \\
\hline & & & 1155.660 & LXXANSXXLPR & & \\
\hline & & & 1219.767 & LFRTTLDVVR & & \\
\hline & & & 1574.816 & ARQLFRTTLDVVR & & \\
\hline & & & 2025.776 & ALLYYS & & \\
\hline & & & 3038.312 & WEKLGQALEGSDVVLLPAGV & & \\
\hline 116 & gil1168493 & Arginase & 896.468 & LMEGGYAR & $1.5 \mathrm{e}-31$ & 376 \\
\hline & & & 954.704 & RLLQVGL & & \\
\hline & & & 1035.437 & YSHASPFAR & & \\
\hline & & & 1100.589 & VLDASLTLLR & & \\
\hline & & & 1158.365 & FREQYEMR & & \\
\hline & & & 1527.785 & VLTDVGDLAVKELR & & \\
\hline 117 & & - & 1271.751 & HLAVFVEXXPR & & \\
\hline 118 & & - & 925.531 & ELLTFFR & & \\
\hline & & & 950.637 & GYTPLFPR & & \\
\hline & & & 991.524 & DHCTFVGR & & \\
\hline & & & 1010.567 & LLAVDLNPR & & \\
\hline 126 & gil1352461 & IN2-2 protein & 1310.505 & DVEAHLLNPFR & $7.8 \mathrm{e}-16$ & 156 \\
\hline & & & 1367.628 & YLGLSEASASTLR & & \\
\hline & & & 1436.618 & LXXGLVAYSPLGR & & \\
\hline
\end{tabular}




\begin{tabular}{|c|c|c|c|c|c|c|}
\hline Spot & $\begin{array}{l}\text { Accession } \\
\text { number }\end{array}$ & Protein & $\begin{array}{l}\text { Precursor } \\
\text { ion }\end{array}$ & Sequence & E-score & $\begin{array}{l}\text { MS-Blast } \\
\text { score }\end{array}$ \\
\hline & & & 1436.618 & TLSNDDXXR & & \\
\hline & & & 1621.745 & LXXCVDLGLRQHR & & \\
\hline \multirow[t]{2}{*}{127} & & - & 1209.330 & VXXDFGDFRR & & \\
\hline & & & 1677.667 & GAXXNTTV & & \\
\hline 133 & & - & 1094.531 & AYNDDDLLR & & \\
\hline \multirow[t]{3}{*}{134} & & - & 1126.420 & EXXXXFALVR & & \\
\hline & & & 1260.318 & YXXEEYLSR & & \\
\hline & & & 1429.453 & FFXXXFGNDXXR & & \\
\hline \multirow[t]{4}{*}{135} & gil51701846 & 26S proteasome non-ATPase regulatory subunit 14 & 819.413 & VVLDAFR & $3.1 \mathrm{e}-10$ & 146 \\
\hline & & & 961.249 & WTDGLTLR & & \\
\hline & & & 1300.408 & ALNYR & & \\
\hline & & & 1658.389 & GFLGQER & & \\
\hline \multirow[t]{3}{*}{136} & gil1708422 & Isoflavone reductase homolog & 1096.635 & AGHPTFVLLR & $9.6 \mathrm{e}-13$ & 189 \\
\hline & & & 1429.639 & FFPSEFGNDVDR & & \\
\hline & & & 1706.028 & AVXXNVLLSLR & & \\
\hline \multirow[t]{6}{*}{139} & gil75337884 & Annexin D1 & 1114.533 & SSYELFNVR & $1.9 \mathrm{e}-13$ & 357 \\
\hline & & & 1254.128 & DHGDTSGD & & \\
\hline & & & 1344.735 & ALVLFTLDPAER & & \\
\hline & & & 1425.587 & SLDKELSSDFER & & \\
\hline & & & 1617.870 & LXXKHYNDEEVLR & & \\
\hline & & & 1844.028 & VXXYLFELACTR & & \\
\hline \multirow[t]{3}{*}{140} & gil1708421 & Isoflavone reductase homolog IRL & 997.604 & GHXXFALVR & $1.4 \mathrm{e}-15$ & 206 \\
\hline & & & 1260.615 & YTTVEEYLSR & & \\
\hline & & & 1429.725 & FFPSEFGNDVDR & & \\
\hline 146 & gil1351279 & Triose-phosphate isomerase, cytosolic & 954.440 & FFVGGN & $6.0 \mathrm{e}-21$ & 218 \\
\hline & & & 1628.846 & WLQANVSPEVAASTR & & \\
\hline & & & 1763.837 & VXXXXQAQEVHSELR & & \\
\hline 150 & & - & 1100.470 & GXXGELQQDR & & \\
\hline & & & 1117.479 & CVLLEGSSPR & & \\
\hline & & & 1347.475 & LTSCFR & & \\
\hline & & & 1039.544 & VNAVAPSLLR & & \\
\hline & & & 1347.475 & LLXXLTSCFR & & \\
\hline & & & 1441.487 & HLACEWAGDNLR & & \\
\hline & & & 1562.830 & GXXHALVEELAXXKR & & \\
\hline & & & 1895.053 & ASGPGSLVLLSSLAGLTXXR & & \\
\hline 151 & gil75331395 & Probable calcium-binding protein CML49 & 1039.539 & VNAVAPSLLR & $8.5 \mathrm{e}-06$ & 83 \\
\hline & & & 1372.642 & ALSSYNQSFSLR & & \\
\hline & & & 1895.043 & VLLSSLA & & \\
\hline 152 & gil75331395 & Probable calcium-binding protein CML49 & 1372.597 & ALSSYNKSFSLR & $1.2 \mathrm{e}-12$ & 131 \\
\hline & & & 1660.782 & VFYSLQNWR & & \\
\hline 154 & & - & 899.559 & TVAGALVLR & & \\
\hline & & & 1498.745 & SLGLSNYDLFLTR & & \\
\hline & & & 1926.997 & KXXVNKLETHPYXXR & & \\
\hline 156 & & - & 1447.938 & NXXLSCDXXFR & & \\
\hline 159 & & - & 1012.444 & FQGENFDR & & \\
\hline & & & 1116.568 & NLDGNLDSLR & & \\
\hline & & & 1254.584 & FQWNFDXXXR & & \\
\hline & & & 1418.684 & AXXESVPANSFLR & & \\
\hline & & & 1536.716 & YLGLSEASPETLTR & & \\
\hline 161 & gil121345 & Glutamine synthetase PR-2 & 1610.599 & HQEHLAAYWXXER & $9.6 e-13$ & 151 \\
\hline & & & 1803.909 & HETADLNSFSWGVXXR & & \\
\hline 163 & gil2499498 & Phosphoglycerate kinase, cytosolic & 981.422 & VLLSSHLGR & $5.1 \mathrm{e}-26$ & 295 \\
\hline & & & 1072.571 & YXXAGPLVPR & & \\
\hline & & & 1206.750 & VLLSSHLGKPR & & \\
\hline & & & 1808.115 & LXXLXXGGVLLLENVR & & \\
\hline & & & 2075.899 & VDLNVPLDDNFNLTDDTR & & \\
\hline 165 & gil2499499 & Phosphoglycerate kinase, cytosolic & 1072.769 & YSLKPLVPR & $5.3 \mathrm{e}-30$ & 271 \\
\hline & & & 1806.800 & LXXXLXXGGVLLLENVR & & \\
\hline & & & 2074.957 & VDLNVPLDDNFNLTDDTR & & \\
\hline 170 & & - & 800.459 & ELAAAGLR & & \\
\hline & & & 863.343 & GXXQLNR & & \\
\hline 171 & gil229891797 & $\alpha$-1,4-glucan-protein synthase [UDP-forming] & 839.482 & GYFPSLR & $8.8 \mathrm{e}-08$ & 95 \\
\hline & & & 1501.480 & VPEGFDYELYNR & & \\
\hline 172 & & - & 915.565 & GKTPLFPR & & \\
\hline 173 & gil30173108 & Leucoanthocyanidin dioxygenase & 2459.183 & WXXTPSDYTEVTSEYAR & $7.0 \mathrm{e}-08$ & 110 \\
\hline 174 & & - & 1306.746 & VLACFSNNLLR & & \\
\hline & & & 1790.903 & DTFSWRANR & & \\
\hline & & & 1950.511 & ADXXLFNVGNXXNEVXXR & & \\
\hline 175 & gil75163801 & L,L-diaminopimelate aminotransferase & 870.462 & YAGFTGVR & $3.9 \mathrm{e}-59$ & 540 \\
\hline & & & 1059.424 & YANLEYMR & & \\
\hline & & & 1075.438 & YGQLENVPR & & \\
\hline & & & 1363.642 & LQAGYLFPEVAR & & \\
\hline & & & 1442.692 & NAXXVWVHFXXR & & \\
\hline & & & 1813.387 & YTXXDGFFDPLSTVAR & & \\
\hline & & & 1986.874 & THLVTTPGSGFGPGGEXXLR & & \\
\hline & & & 2052.824 & TDLLFFCSXXNPTGAAATR & & \\
\hline 176 & & - & 909.483 & NCSLLFR & & \\
\hline & & & 1100.590 & LLSATEPTLR & & \\
\hline
\end{tabular}




\begin{tabular}{|c|c|c|c|c|c|c|}
\hline Spot & $\begin{array}{l}\text { Accession } \\
\text { number }\end{array}$ & Protein & $\begin{array}{l}\text { Precursor } \\
\text { ion }\end{array}$ & Sequence & E-score & $\begin{array}{c}\text { MS-Blast } \\
\text { score }\end{array}$ \\
\hline & & & 1572.873 & VLSGTDLTXXR & & \\
\hline \multirow[t]{2}{*}{177} & gil1345655 & Cinnamyl alcohol dehydrogenase 4 & 1074.517 & HFGLMGSGLR & $3.9 \mathrm{e}-13$ & 149 \\
\hline & & & 1868.429 & FTVGELVGVGCVVGCCR & & \\
\hline \multirow[t]{5}{*}{178} & gil119194 & Elongation factor $\mathrm{Tu}$, chloroplastic & 1173.671 & TXXTVDLVGLR & $3.2 \mathrm{e}-34$ & 339 \\
\hline & & & 1435.686 & KYDELDAAPEER & & \\
\hline & & & 1703.585 & AGDNVGLLLR & & \\
\hline & & & 1810.609 & GXXLNTATVEYETENR & & \\
\hline & & & 1919.792 & FXXACEKXXR & & \\
\hline \multirow[t]{2}{*}{179} & gil12644295 & Phosphoglycerate, chloroplastic & 989.531 & FSLAPLVSR & $6.4 \mathrm{e}-17$ & 117 \\
\hline & & & 2062.916 & ADXXVPLDDNQNLTDDTR & & \\
\hline \multirow[t]{3}{*}{180} & gil231502 & Actin-85C & 945.480 & AVFPSLVGR & $9.3 \mathrm{e}-13$ & 177 \\
\hline & & & 1132.486 & GYSFTTTAER & & \\
\hline & & & 1747.788 & VLTLKER & & \\
\hline \multirow[t]{4}{*}{181} & gil231503 & Actin-85C & 945.591 & AVFPSLVGR & $1.1 \mathrm{e}-19$ & 209 \\
\hline & & & 976.572 & AXXAGDDAPR & & \\
\hline & & & 1130.729 & GYSFTTTAER & & \\
\hline & & & 1384.556 & SFTTTAER & & \\
\hline 182 & & - & 1610.760 & HLAAYW & & \\
\hline \multirow[t]{4}{*}{183} & & - & 642.503 & HAFDR & & \\
\hline & & & 1012.547 & FKGENFDR & & \\
\hline & & & 1116.584 & NLDGNLDSL & & \\
\hline & & & 1704.943 & LDATGVLVDGTPEYVR & & \\
\hline 184 & & - & 1469.889 & ATVFAHETFGAYR & & \\
\hline & & & 855.568 & SPAQLSPR & & \\
\hline & & & 1019.678 & LXXLFEVAR & & \\
\hline & & & 1037.660 & FSELEKER & & \\
\hline & & & 1147.717 & KXXLFEVAR & & \\
\hline 185 & & - & 784.438 & VXXLGLGR & & \\
\hline & & & 827.466 & GVLLNVGR & & \\
\hline & & & 1550.750 & SCPLSYYSR & & \\
\hline 186 & & - & 899.442 & DTQPGLLR & & \\
\hline & & & 1227.684 & HLESLEGAESR & & \\
\hline & & & 1449.837 & VAELYPEYNVPR & & \\
\hline 187 & gil75313643 & Malate dehydrogenase, chloroplastic & 1219.841 & LFRTTLDVVR & $2.2 \mathrm{e}-06$ & 90 \\
\hline & & & 1276.779 & GVNVVVLPAGVPR & & \\
\hline 188 & & - & 800.368 & VYLLHR & & \\
\hline & & & 1007.000 & VDLSSSPFR & & \\
\hline 189 & & - & 862.594 & VLAFEAGR & & \\
\hline & & & 1027.566 & VNTLSAGPLR & & \\
\hline & & & 1260.704 & YXXVEEYLSR & & \\
\hline & & & 1429.852 & FFPSEFGNDVDR & & \\
\hline 191 & & - & 869.511 & GTFLEFR & & \\
\hline & & & 1289.679 & YLSGVNLPVDGR & & \\
\hline & & & 1322.653 & SLSVELGEYGLR & & \\
\hline & & & 1389.612 & HELFEXXR & & \\
\hline & & & 1559.823 & VXXLTGGASGLGESTAR & & \\
\hline 192 & & - & 1071.484 & NLEEWPQR & & \\
\hline & & & 1147.603 & GFTGGLNYYR & & \\
\hline 193 & gil74683233 & Protein transport SEC13 & 964.310 & ADNWDTSR & $2.3 \mathrm{e}-05$ & 159 \\
\hline & & & 1383.606 & VLHDFNTXXWR & & \\
\hline & & & 1432.585 & FXXLLASCSYDGR & & \\
\hline 194 & & - & 819.374 & LAWATSQR & & \\
\hline & & & 1026.520 & VDLPELQGR & & \\
\hline & & & 1229.610 & LGCQSPVEALR & & \\
\hline 196 & & - & 1641.761 & YVNTGASWVTGAFNR & & \\
\hline 197 & & - & 905.437 & FLHAVYR & & \\
\hline & & & 1034.523 & KVDRCNSR & & \\
\hline 198 & gil74996477 & Probable 3-hydroxyisobutyrate dehydrogenase & 854.534 & LFNCSSAR & $1.2 \mathrm{e}-06$ & 119 \\
\hline & & & 1092.507 & YXXFFQMR & & \\
\hline & & & 1545.726 & LXXDSSTLDXXTSR & & \\
\hline 199 & gil51316816 & Photosystem I assembly protein Ycf4 & 1049.496 & ALVSLEYVR & $7.6 \mathrm{e}-03$ & 68 \\
\hline & & & 1962.071 & SXXYVKVSXXQSLPLTR & & \\
\hline 205 & gil1351963 & L-ascorbate peroxidase, cytosolic & 990.479 & NCAPLFLR & $9.2 \mathrm{e}-22$ & 276 \\
\hline & & & 1258.613 & EDZPHPPPEGR & & \\
\hline & & & 1243.534 & CYPTVSEEYR & & \\
\hline & & & 1846.879 & KXXLAHGANDGLDLAVR & & \\
\hline 208 & & - & 1032.488 & VXXELTLAR & & \\
\hline 209 & & - & 1895.926 & AKLQEVLLSSLAXXTXXR & & \\
\hline 210 & gil1717752 & Tropinone reductase 1 & 1467.674 & YLACEWAGDNLR & $2.2 \mathrm{e}-12$ & 192 \\
\hline & & & 1562.735 & GXXALVEELAGLGAR & & \\
\hline & & & 1878.954 & ANTGSVVLLSSLAGLLXXR & & \\
\hline 211 & & - & 1036.371 & VLDLYEER & & \\
\hline 215 & & - & 943.436 & FYNDQTR & & \\
\hline & & & 1059.375 & KALKHYGSR & & \\
\hline & & & 1134.402 & YDGFVYTNR & & \\
\hline & & & 2286.889 & FXXMWGNSYYSALESGFSDR & & \\
\hline 216 & & - & 943.375 & FYNDQTR & & \\
\hline & & & 994.453 & VLDVYETVR & & \\
\hline
\end{tabular}




\begin{tabular}{|c|c|c|c|c|c|c|}
\hline Spot & $\begin{array}{l}\text { Accession } \\
\text { number }\end{array}$ & Protein & $\begin{array}{l}\text { Precursor } \\
\text { ion }\end{array}$ & Sequence & E-score & $\begin{array}{l}\text { MS-Blast } \\
\text { score }\end{array}$ \\
\hline 217 & & - & 1641.775 & TTANQDXXV & & \\
\hline \multirow[t]{4}{*}{219} & & - & 975.466 & NHLQPNPR & & \\
\hline & & & 1113.755 & VVTALTLLKR & & \\
\hline & & & 1151.596 & LXXLHSVAER & & \\
\hline & & & 1989.031 & LFQDRLLQD & & \\
\hline \multirow[t]{3}{*}{220} & gil225446793 & Glutathione S-transferase 3 & 1036.471 & VLDLYEER & $2.6 \mathrm{e}-05$ & 112 \\
\hline & & & 1215.412 & GEHKD & & \\
\hline & & & 2397.464 & TQDXXYLLYESR & & \\
\hline \multirow[t]{2}{*}{222} & & - & 1022.480 & TWSTPFGAR & & \\
\hline & & & 1804.707 & AXXPDVLGDCXXCQR & & \\
\hline \multirow[t]{3}{*}{223} & gil75334429 & GSH-dependent dehydroascorbate reductase 1 & 1081.478 & LYQFEXXR & $4.9 \mathrm{e}-07$ & 78 \\
\hline & & & 1307.779 & NLSDQPR & & \\
\hline & & & 1804.543 & AXXAXXVLGDCPFCQR & & \\
\hline \multirow[t]{6}{*}{224} & gil17380179 & $20 \mathrm{~S}$ proteasome $\beta$ subunit $\mathrm{D}$, type 2 & 821.393 & CLMELR & $4.0 \mathrm{e}-26$ & 281 \\
\hline & & & 830.524 & GELATALR & & \\
\hline & & & 873.429 & LVDKDGAR & & \\
\hline & & & 1010.468 & NVALYQFR & & \\
\hline & & & 1075.429 & AASWSXXR & & \\
\hline & & & 1518.753 & NXXPLTTAAAANFTR & & \\
\hline \multirow[t]{5}{*}{225} & gil1360571 & Triose-phosphate isomerase, cytosolic & 807.298 & FFVGGNXXR & $2.4 \mathrm{e}-32$ & 327 \\
\hline & & & 1117.306 & DNVGAGVAASTR & & \\
\hline & & & 1438.551 & ALLNESNEFVSSR & & \\
\hline & & & 1589.620 & SDFHVAAQNCWVR & & \\
\hline & & & 1708.670 & VXXPAQAKEVHCELR & & \\
\hline 226 & gil22096383 & Uncharacterized protein & 1858.893 & ELLVGKDDELLQTETR & $2.6 \mathrm{e}-08$ & 103 \\
\hline 227 & gil1172601 & Probable proteasome subunit $\alpha$ type- 4 & 1007.424 & TTLFSPEGR & $2.2 \mathrm{e}-03$ & 64 \\
\hline 228 & & - & 1258.663 & EDKPHPPXXR & & \\
\hline 229 & & - & 857.483 & LLAWAQR & & \\
\hline & & & 1487.657 & SXXXFVASD & & \\
\hline 230 & & - & 938.207 & EFLEXXR & & \\
\hline 231 & gil12643263 & Chaperonin 10 & 970.626 & DLKPLGGDR & $1.1 \mathrm{e}-10$ & 161 \\
\hline & & & 1149.740 & YTSLKPLGDR & & \\
\hline & & & 1166.747 & GSDGTNYLALR & & \\
\hline 232 & & - & 931.491 & KAEQYHR & & \\
\hline & & & 1552.296 & TQLVR & & \\
\hline & & & 1150.820 & EXXXXTQLVR & & \\
\hline 233 & & - & 1542.813 & FLTLDGD & & \\
\hline 234 & gil73921673 & Allene oxide cyclase 3 , chloroplastic & 1034.587 & DRGSPAYLR & $2.6 \mathrm{e}-04$ & 149 \\
\hline & & & 1554.853 & VQELYVYELNER & & \\
\hline 249 & gil1346675 & Nucleoside diphosphate kinase B & 913.588 & GLVGELLGR & $3.2 \mathrm{e}-27$ & 245 \\
\hline & & & 1370.616 & NVLHGSDSVESAR & & \\
\hline & & & 1567.770 & LLGATNPAESAPGTLR & & \\
\hline 250 & gil14285792 & T-complex protein 1 subunit $\gamma$ & 1132.550 & SXXPTVLCR & $1.3 \mathrm{e}-05$ & 130 \\
\hline & & & 1344.610 & TLAQNCGVNVLR & & \\
\hline 251 & gil109909540 & Formate dehydrogenase 1 , mitochondrial & 868.308 & GMFDKDR & $3.9 \mathrm{e}-41$ & 448 \\
\hline & & & 955.587 & GVLLVNNAR & & \\
\hline & & & 1062.548 & EWLAPYYR & & \\
\hline & & & 1174.688 & LSXXTLDAQLR & & \\
\hline & & & 1492.629 & FVGCVEKVXXR & & \\
\hline & & & 1602.570 & NXXFVGCVEGALGLR & & \\
\hline & & & 1689.597 & LKXXNCNLLYHDR & & \\
\hline & & & 2328.332 & TXXLSGTTLD & & \\
\hline & & & 3004.513 & KYLVTDDKE & & \\
\hline 252 & & - & 1012.551 & LLQEGSXXR & & \\
\hline & & & 1148.775 & HXXSHQWPR & & \\
\hline & & & 1179.561 & KLTAGR & & \\
\hline 255 & gil30315948 & Caffeic acid 3-O-methyltransferase & 924.480 & FNKVFNR & $1.8 \mathrm{e}-18$ & 198 \\
\hline & & & 1014.520 & TLPDGKVER & & \\
\hline & & & 1715.588 & AXXXXAFEYHGTDPR & & \\
\hline 256 & gil231502 & Actin-85C & 976.416 & AXXAGDDAPR & $7.3 e-12$ & 146 \\
\hline & & & 1132.465 & GYSFTTTAER & & \\
\hline 257 & gil2500522 & Eukaryotic initiation factor $4 \mathrm{~A}$ & 976.595 & GXXLNFVTR & $1.3 \mathrm{e}-20$ & 181 \\
\hline & & & 1114.662 & VLLTTDLLAR & & \\
\hline & & & 1518.943 & LXXSGVHVVGTXXR & & \\
\hline & & & 1826.750 & YGFEQPSALKQR & & \\
\hline 258 & & - & 965.441 & KVLTYWR & & \\
\hline & & & 1017.406 & SVYTGGDYR & & \\
\hline & & & 1148.448 & SXXLFNLESR & & \\
\hline & & & 1494.672 & EVEALNNVHAGVSR & & \\
\hline 260 & gil26391492 & ATP synthase subunit $\beta-2$, mitochondrial & 1118.613 & HYLPLHR & $2.6 \mathrm{e}-06$ & 125 \\
\hline & & & 1492.808 & FTKKANSEVSALLGR & & \\
\hline 261 & gil189045124 & Glucose-6-phosphate isomerase & 917.554 & LAMKWLR & $1.4 \mathrm{e}-03$ & 173 \\
\hline & & & 1458.792 & EXXTVTVKEVTPR & & \\
\hline & & & 1515.668 & GXXZHAYLQKLR & & \\
\hline 262 & gil21759093 & Betaine aldehyde dehydrogenase 1 & 1009.454 & LLVHEXXR & $8.5 e-24$ & 304 \\
\hline & & & 1129.338 & KLLLDGEWR & & \\
\hline & & & 1175.441 & LSDPLEEGC & & \\
\hline & & & 1230.485 & GQDWALASGAVR & & \\
\hline
\end{tabular}




\begin{tabular}{|c|c|c|c|c|c|c|}
\hline Spot & $\begin{array}{c}\text { Accession } \\
\text { number }\end{array}$ & Protein & $\begin{array}{l}\text { Precursor } \\
\text { ion }\end{array}$ & Sequence & E-score & $\begin{array}{c}\text { MS-Blast } \\
\text { score }\end{array}$ \\
\hline & & & 1913.763 & KVTKYVSDEPWGWYR & & \\
\hline \multirow[t]{3}{*}{263} & gil62900360 & Importin subunit $\alpha-1 \mathrm{a}$ & 1369.611 & NATWTLSNFCR & $5.3 e-16$ & 260 \\
\hline & & & 1590.773 & SXXEEVLQAGVVPR & & \\
\hline & & & 2502.173 & KXXCDLLNCXXR & & \\
\hline \multirow[t]{4}{*}{264} & gil585451 & NAD-dependent malic enzyme $62 \mathrm{kDa}$ isoform, mitochondrial & 1500.850 & LDLYVAAAGLNPQR & $8.8 \mathrm{e}-30$ & 311 \\
\hline & & & 1595.921 & LVVAGAGSAGLGVLNAAR & & \\
\hline & & & 1693.716 & LXXDXXYLGLQQHR & & \\
\hline & & & 2829.320 & VGDNLLFAXXR & & \\
\hline \multirow[t]{7}{*}{265} & gil401322 & V-type proton ATPase catalytic subunit A & 1216.634 & FDKDFLYLR & $3.2 \mathrm{e}-64$ & 562 \\
\hline & & & 1255.724 & LAADTPLLTGQR & & \\
\hline & & & 1335.677 & VGHDNLLGELLR & & \\
\hline & & & 1675.658 & YSNSDAVVYVGCWR & & \\
\hline & & & 1733.799 & EXXLYTGLTLAEYFR & & \\
\hline & & & 2052.816 & LXXFEDSEKESEYGYVR & & \\
\hline & & & 2691.582 & NXXXXTNKVYEETAGLTVNDXXLR & & \\
\hline \multirow[t]{3}{*}{266} & & - & 1018.464 & KXXATYGR & & \\
\hline & & & 1139.584 & SLFDFELLR & & \\
\hline & & & 2005.704 & ALHRAQYR & & \\
\hline \multirow[t]{3}{*}{267} & gil399940 & Heat shock $70 \mathrm{kDa}$ protein, mitochondrial & 1419.773 & DVDEVLL & $2.2 \mathrm{e}-20$ & 235 \\
\hline & & & 1564.686 & AVLTVPAYFNDAQR & & \\
\hline & & & 1955.632 & EAVAFGAALQGGLLR & & \\
\hline \multirow[t]{4}{*}{276} & gil2506277 & RuBisCO subunit binding-protein $\beta$ subunit, chloroplastic & 1229.615 & LAALKAPGFWR & $2.2 \mathrm{e}-26$ & 296 \\
\hline & & & 1280.737 & VVAAGANPVLLTR & & \\
\hline & & & 1679.779 & EAAEZDYEXXR & & \\
\hline & & & 1819.818 & DXXTLVGDGSTQGAVNKR & & \\
\hline 277 & gil190358177 & ATP synthase $\alpha$ subunit, chloroplast & 815.407 & ELLLXXR & $2.8 \mathrm{e}-76$ & 656 \\
\hline & & & 822.369 & LEQYNR & & \\
\hline & & & 876.434 & KFSLLLR & & \\
\hline & & & 904.628 & KMEVELR & & \\
\hline & & & 1030.530 & ADELSNLLR & & \\
\hline & & & 1093.515 & DRLEKYNR & & \\
\hline & & & 1252.711 & LLESPAPGLLSR & & \\
\hline & & & 1266.670 & ALAKPLDGR & & \\
\hline & & & 1266.670 & SPAPGLLSR & & \\
\hline & & & 1416.836 & LAQLPVSEAYLGR & & \\
\hline & & & 1522.767 & ASSVAQVVTTFZER & & \\
\hline & & & 1553.641 & EAYPGDVFYLHSR & & \\
\hline & & & 1612.961 & LVNTGTVLQVGDGLAR & & \\
\hline 285 & gil1703131 & Actin 12 & 1132.570 & GYSFTTTAER & $2.0 \mathrm{e}-24$ & 230 \\
\hline & & & 1198.730 & TTTAER & & \\
\hline & & & 1445.531 & ESGPSLVHR & & \\
\hline & & & 1962.000 & SXXLPDGQVLTLGAER & & \\
\hline 287 & gil21759255 & 3-isopropylmalate dehydrogenase 2 & 805.444 & VAFELAR & $4.0 \mathrm{e}-10$ & 112 \\
\hline & & & 1337.718 & YFGQPR & & \\
\hline & & & 2064.762 & NTEVYATHEXXR & & \\
\hline 288 & gil399785 & Glutamate-1-semialdehyde 2,1-aminomutase, chloroplastic & 1180.535 & KLTAGR & $1.0 \mathrm{e}-07$ & 90 \\
\hline & & & 1286.604 & LLGGGLPVGAYGGR & & \\
\hline 289 & gil75261432 & Succinyl-CoA ligase [GDP-forming] subunit $\beta$ & 801.491 & SKLLAGGR & $1.1 \mathrm{e}-13$ & 160 \\
\hline & & & 1182.432 & LNFDDNAAFR & & \\
\hline & & & 1185.522 & TAPPLLLACR & & \\
\hline 290 & gil17366963 & Adenosine kinase 2 & 1332.549 & DXXAAAMGLFGPR & $1.3 \mathrm{e}-13$ & 153 \\
\hline & & & 1351.677 & AXXYASNVLLQR & & \\
\hline & & & 1903.657 & DFVFGNETEAR & & \\
\hline 291 & & - & 1335.694 & AXXXAANVLLKR & & \\
\hline & & & 1410.611 & SLVANLSAAN & & \\
\hline 293 & & - & 861.517 & YKVGAXXR & & \\
\hline & & & 1411.764 & LLT & & \\
\hline 294 & gil2493895 & Cysteine synthase; CSase; O-acetylserin & 1359.545 & AFGAELVLTDPAR & $5.4 \mathrm{e}-23$ & 215 \\
\hline & & & 1427.825 & YLSSVLFESVKR & & \\
\hline & & & 2071.175 & ESAVLSGGQ & & \\
\hline L296 & & - & 964.539 & EYEALALR & & \\
\hline 298 & gil148872800 & DNA-damage-repair/toleration protein & 2024.803 & YDXXXGDYLFTPAGDVHR & $7.9 \mathrm{e}-09$ & 107 \\
\hline 299 & gil18202458 & $\alpha$-soluble NSF attachment protein & 1206.600 & ALELYEELAR & $1.4 \mathrm{e}-18$ & 218 \\
\hline & & & 1257.596 & GDVVALTNALER & & \\
\hline & & & 1413.562 & YQELDPTFSGTR & & \\
\hline 300 & gil11134054 & Oxygen-evolving enhancer protein 1 & 958.473 & NAPPEFQR & $6.1 \mathrm{e}-21$ & 208 \\
\hline & & & 1456.602 & SFPAFATTGDDATR & & \\
\hline & & & 1759.772 & DXXYAAVTVQL & & \\
\hline & & & 2253.742 & KLVASGQPESFGGDFLVXXYR & & \\
\hline 308 & & - & 1107.511 & DTLDLFVER & & \\
\hline & & & 1314.647 & GQDLSVVAGLEAR & & \\
\hline 309 & gil224146220 & Chalcone isomerase-like protein & 852.395 & WYLGGTR & $4.2 \mathrm{e}-16$ & 157 \\
\hline & & & 1393.612 & GSQYGVQLESAVR & & \\
\hline & & & 1632.741 & GXXTTLTSLANALSAR & & \\
\hline 310 & & - & 960.498 & ALLPDLYR & & \\
\hline & & & 971.347 & FGASWFTR & & \\
\hline & & & 1393.694 & GXXYGVKLESAVR & & \\
\hline 316 & & - & 947.520 & TALQVPYR & & \\
\hline
\end{tabular}




\begin{tabular}{|c|c|c|c|c|c|c|}
\hline Spot & $\begin{array}{l}\text { Accession } \\
\text { number }\end{array}$ & Protein & $\begin{array}{l}\text { Precursor } \\
\text { ion }\end{array}$ & Sequence & E-score & $\begin{array}{l}\text { MS-Blast } \\
\text { score }\end{array}$ \\
\hline & & & 1025.428 & NLYLLFSR & & \\
\hline & & & 1429.588 & GYXXSDLPPEPER & & \\
\hline & & & 1580.689 & FHQSLPEGFYLSR & & \\
\hline \multirow[t]{2}{*}{317} & gil461461 & Enoyl-[acyl-carrier-protein] reductase & 862.514 & VLAFEAGR & $3.4 \mathrm{e}-08$ & 121 \\
\hline & & & 1027.554 & VNTLSAGPLR & & \\
\hline \multirow[t]{3}{*}{318} & gil8928330 & 40S Ribosomal protein SA (p40) & 940.612 & LLLLTDPR & $4.7 \mathrm{e}-17$ & 128 \\
\hline & & & 1115.298 & NCDYQMER & & \\
\hline & & & 1336.537 & FXXHTGAHALAGR & & \\
\hline \multirow[t]{2}{*}{319} & & - & 1009.598 & LFHS & & \\
\hline & & & 1172.759 & YLLHDENLR & & \\
\hline \multirow[t]{5}{*}{320} & gil225464635 & Hypothetical protein & 828.502 & EVTVKPR & $6.6 \mathrm{e}-11$ & 229 \\
\hline & & & 901.475 & LLPDKCR & & \\
\hline & & & 951.491 & NAELYADR & & \\
\hline & & & 1413.774 & AXXETGAALAPGESR & & \\
\hline & & & 1496.595 & WEDTRR & & \\
\hline \multirow[t]{2}{*}{321} & & - & 866.602 & LLQLHSR & & \\
\hline & & & 1062.692 & EEFQR & & \\
\hline \multirow[t]{6}{*}{322} & gil54036493 & Tubulin $\alpha$-2 chain; $\alpha$-2-tubulin & 1007.507 & EDAANFAR & $2.1 \mathrm{e}-38$ & 484 \\
\hline & & & 1132.530 & ELVDLCLDR & & \\
\hline & & & 1299.468 & QVPPCLFYR & & \\
\hline & & & 1598.779 & TLQFVDWC & & \\
\hline & & & 1857.795 & LSNSTSVAEVFSR & & \\
\hline & & & 1977.921 & TVXXDAFNTFFSE & & \\
\hline 323 & & - & 809.390 & SLLSFSR & & \\
\hline & & & 1079.533 & TLVSLEYVR & & \\
\hline & & & 1209.596 & LTSGDSTLFLR & & \\
\hline & & & 1262.555 & GTLKLGYQNLR & & \\
\hline & & & 1313.577 & YXXVTVGYSVVR & & \\
\hline & & & 1484.582 & NENLTFANYDKR & & \\
\hline & & & 1555.610 & LKQSFGTFSSAVQR & & \\
\hline & & & 1662.716 & LXXSGSYVDGYNVVR & & \\
\hline & & & 1837.836 & NWTAVVAAADTGGVSYVR & & \\
\hline & & & 1947.738 & PXXASAAFNVDEND & & \\
\hline 324 & & - & 941.603 & VLELALKR & & \\
\hline & & & 1518.742 & EXXKL & & \\
\hline 325 & gil229464991 & Heat shock $70 \mathrm{kDa}$ protein & 1197.650 & FELSGLPXXXR & $2.9 \mathrm{e}-32$ & 240 \\
\hline & & & 1228.724 & VELLANDKGNR & & \\
\hline & & & 1412.986 & SWHDVVLVGGSTR & & \\
\hline & & & 1487.880 & TTPSYVAFTDTER & & \\
\hline 327 & gil123592 & Heat shock $70 \mathrm{kDa}$ protein & 1197.653 & FELSGLPXXXR & $7.2 \mathrm{e}-22$ & 228 \\
\hline & & & 1412.723 & SWHDVVLVGGSTR & & \\
\hline & & & 1473.564 & TTPSYVAFTDSER & & \\
\hline 335 & gil1708311 & Stromal $70 \mathrm{kDa}$ heat shock-related protein & 970.483 & HLETXXXR & $4.3 e-31$ & 362 \\
\hline & & & 1058.569 & FPAQELVR & & \\
\hline & & & 1156.541 & LQTELVER & & \\
\hline & & & 1373.753 & LDEVLLVGGSTR & & \\
\hline & & & 1461.731 & QFAAEELSAKVLR & & \\
\hline & & & 1566.854 & AVVTVPAYFNDSQR & & \\
\hline & & & 1623.937 & ELCSDLLDR & & \\
\hline 339 & gil123656 & Chloroplast envelope membrane $70 \mathrm{kDa}$ heat shock protein & 1329.706 & LNFDLFR & $1.6 \mathrm{e}-22$ & 233 \\
\hline & & & 1426.866 & STVHDVVLVGGSTR & & \\
\hline & & & 1487.769 & TTPSYVAFTDTER & & \\
\hline 343 & & - & 1950.843 & AHGADAY & & \\
\hline 348 & & - & 1002.536 & GYPTVYFR & & \\
\hline & & & 1309.850 & YXXTVGYXXVR & & \\
\hline 349 & gil11133775 & Protein disulfide isomerase & 1002.463 & GYPTVYFR & $5.3 \mathrm{e}-06$ & 128 \\
\hline & & & 1421.688 & SADGNLKPYEGDR & & \\
\hline 354 & gil223635791 & Transaldolase & 1084.492 & LXXPEALDLR & $5.7 \mathrm{e}-06$ & 69 \\
\hline & & & 1199.580 & VTWASFTVSR & & \\
\hline & & & 1472.758 & AXXSSNAYNDQFR & & \\
\hline 355 & gil123142886 & Transaldolase & 1084.667 & LGTPEALDLR & $3.2 \mathrm{e}-10$ & 232 \\
\hline & & & 1199.604 & VTSVASFFVSR & & \\
\hline & & & 1472.731 & ALSSSNAYNDQFR & & \\
\hline 356 & gil123142886 & Transaldolase & 1084.807 & LGTPEALDLR & $3.2 \mathrm{e}-10$ & 240 \\
\hline & & & 1199.715 & VTSVASFFVSR & & \\
\hline & & & 1472.913 & ALSSSNAYNDQFR & & \\
\hline 358 & & - & 1400.766 & LXXDATAQLLDLR & & \\
\hline 362 & gil12229892 & Proteasome subunit $\alpha$ type-1-B & 840.460 & PATVSLPR & $8.5 \mathrm{e}-25$ & 242 \\
\hline & & & 873.517 & KXXALGLR & & \\
\hline & & & 1679.916 & VDDHLGVALAGLTADGR & & \\
\hline & & & 1596.526 & NXXDTDVTTWSPAGR & & \\
\hline 366 & & - & 960.562 & ALLPDLYR & & \\
\hline & & & 1107.661 & DTLDLFVER & & \\
\hline 368 & gil1345698 & Chlorophyll-a/b binding protein 151 & 1055.533 & ELEVLHCR & $1.8 \mathrm{e}-11$ & 135 \\
\hline & & & 1325.605 & NRELEVLHCR & & \\
\hline & & & 1544.766 & SAPASLWYGA & & \\
\hline 369 & gil115777 & Chlorophyll-a/b binding protein, chloroplastic & 1055.390 & ELEVLHCR & $2.4 \mathrm{e}-04$ & 76 \\
\hline & & & 1179.475 & YEELQLTAAGR & & \\
\hline
\end{tabular}




\begin{tabular}{|c|c|c|c|c|c|c|}
\hline Spot & $\begin{array}{c}\text { Accession } \\
\text { number }\end{array}$ & Protein & $\begin{array}{l}\text { Precursor } \\
\text { ion }\end{array}$ & Sequence & E-score & $\begin{array}{l}\text { MS-Blast } \\
\text { score }\end{array}$ \\
\hline & & & 1325.433 & NRELEVLHCR & & \\
\hline \multirow[t]{4}{*}{372} & gil1168191 & $14-3-3$ protein 4 & 816.458 & LAEQAER & $5.4 \mathrm{e}-18$ & 271 \\
\hline & & & 1418.624 & LSDVEELLSEER & & \\
\hline & & & 1418.624 & TVDVVEQKEESR & & \\
\hline & & & 1802.917 & SXXDLALAELAPTHXXR & & \\
\hline 373 & & - & 1102.555 & NPGDSFPNVR & & \\
\hline \multirow[t]{3}{*}{374} & gil26454610 & $14-3-3$ protein 8 & 816.460 & LAEKAER & $3.0 \mathrm{e}-21$ & 206 \\
\hline & & & 1202.704 & LDVELTVEER & & \\
\hline & & & 2138.979 & AXXTATATAEAELPPTHXXR & & \\
\hline \multirow[t]{6}{*}{376} & gil12230867 & 14-3-3-like protein GF14 $\omega$ & 1093.290 & HVAVLR & $1.9 \mathrm{e}-28$ & 304 \\
\hline & & & 1109.538 & GNEDHVAVLR & & \\
\hline & & & 1205.488 & LFQLLR & & \\
\hline & & & 1418.739 & LLSSLEKKEESR & & \\
\hline & & & 1675.942 & VSASVENEELSVEER & & \\
\hline & & & 1803.833 & LANAELAPTHXXR & & \\
\hline \multirow[t]{6}{*}{377} & gil26454609 & $14-3-3$ protein 7 & 805.443 & LFVLTGR & $3.8 \mathrm{e}-16$ & 232 \\
\hline & & & 932.491 & FKGDYFR & & \\
\hline & & & 1006.471 & EQKVYLAR & & \\
\hline & & & 1205.504 & LLFQLLR & & \\
\hline & & & 1484.786 & NLLFAGYTDWER & & \\
\hline & & & 2084.894 & AXXXAATSTASSDLPPTHXXR & & \\
\hline \multirow[t]{5}{*}{378} & gil12230867 & 14-3-3-like protein GF14 $\omega$ & 922.432 & FKGDYHR & $1.1 \mathrm{e}-27$ & 323 \\
\hline & & & 1667.526 & GNADHVSVLR & & \\
\hline & & & 1374.750 & LVSSLEKKEEGR & & \\
\hline & & & 1803.957 & SXXDLANAELAPTHXXR & & \\
\hline & & & 2247.810 & SAVPAPDELTVEER & & \\
\hline \multirow[t]{2}{*}{379} & & - & 938.600 & YCVGLGNR & & \\
\hline & & & 1125.715 & FLWNR & & \\
\hline 380 & & - & 1109.466 & YNLMLWNR & & \\
\hline 381 & & - & 1061.409 & YXXLWNR & & \\
\hline & & & 1109.451 & YXXMLWNR & & \\
\hline & & & 1990.430 & YWGQNLYE & & \\
\hline 382 & & - & 701.511 & LHFER & & \\
\hline & & & 1723.860 & STYDDLQPGSLL & & \\
\hline & & & 1827.775 & TWLXXXXNKDD & & \\
\hline 385 & gil75294319 & 14-3-3-like protein GF14-C & 808.399 & LDYLER & $8.7 \mathrm{e}-09$ & 150 \\
\hline & & & 1151.807 & LVSLELP & & \\
\hline & & & 1685.144 & AELTVEER & & \\
\hline & & & 1772.946 & LALADLAXXHPLR & & \\
\hline 386 & gil9979193 & Translationally-controlled tumor protein & 1063.475 & VVDLVDTFR & $2.2 \mathrm{e}-03$ & 66 \\
\hline 397 & & - & 1791.434 & NNSLTFR & & \\
\hline & & & 1836.797 & ELVEALDSENNSLTFR & & \\
\hline & & & 2035.930 & AHFWEALDSENNSLTFR & & \\
\hline 410 & gil12585487 & V-type H-ATPase subunit C & 1013.579 & ALNKR & $2.7 \mathrm{e}-17$ & 172 \\
\hline & & & 1457.517 & DFEYSPEAQESR & & \\
\hline & & & & TVDGVXXDSYLTR & & \\
\hline 411 & gil75146893 & Bifunctional dihydroflavanol 4-reductase & 1035.457 & LLEDGYAVR & $5.2 \mathrm{e}-16$ & 198 \\
\hline & & & 1608.665 & LVFTSSAGTVNVEER & & \\
\hline & & & 1848.254 & MFTEAVETCR & & \\
\hline 412 & & - & 967.084 & ALSFSLATR & & \\
\hline & & & 1419.659 & DNFVSLWHFVR & & \\
\hline 413 & gil75038951 & $\alpha$-S1-casein precursor & 1267.712 & YLGYLEQLLR & $1.5 \mathrm{e}-03$ & 70 \\
\hline 414 & gil6225258 & Aspartate semialdehyde dehydrogenase & 1154.638 & NAPGVVVLDDR & $1.8 \mathrm{e}-06$ & 118 \\
\hline & & & 1235.568 & GXXVVDNSSAFR & & \\
\hline 415 & & - & 1156.566 & EXXAYLETGR & & \\
\hline & & & 1613.745 & KXXXAEYTAVEER & & \\
\hline 416 & & - & 1038.569 & GVFPFSQTR & & \\
\hline & & & 1156.481 & EAFAYLETGR & & \\
\hline & & & 1613.676 & KFGTLAEYTAVEER & & \\
\hline 417 & & - & 1038.567 & GVFPFSQTR & & \\
\hline & & & 1156.483 & EAFAYLETGR & & \\
\hline & & & 1473.776 & LAXXEXXWHAXXR & & \\
\hline & & & 1613.659 & QFXXLAEYTAVEER & & \\
\hline 421 & gil14548089 & Inositol-3-phosphate synthase & 1287.704 & VVVLWTANTER & $7.7 \mathrm{e}-29$ & 255 \\
\hline & & & 1574.634 & VXXYDGEELYA & & \\
\hline & & & 2127.200 & DXXQKANYFGSLTQASTLR & & \\
\hline 422 & & - & 2725.866 & TRVVFAGALLEQAER & & \\
\hline 423 & gil12585296 & Phosphoglucomutase, cytoplasmic & 970.568 & FLFEDGSR & $2.5 \mathrm{e}-22$ & 237 \\
\hline & & & 1018.483 & KHWATYGR & & \\
\hline & & & 1139.658 & SLFDFELLR & & \\
\hline & & & 1773.891 & DXXKPGTSXXR & & \\
\hline & & & 2057.053 & ALHRAQYAHR & & \\
\hline & & & 2057.053 & QLVTVEDXXR & & \\
\hline 424 & & - & 1666.001 & VXXKLYLER & & \\
\hline & & & 1666.001 & LYGASGYLFER & & \\
\hline & & & 2251.547 & SSDVALLASNKLDQDR & & \\
\hline 427 & gil75338403 & ATP synthase subunit $\beta$, chloroplastic & 1328.509 & AHGGVSVFGGVGER & $2.2 \mathrm{e}-50$ & 447 \\
\hline & & & 1471.694 & VXXALTMAEYFR & & \\
\hline
\end{tabular}




\begin{tabular}{|c|c|c|c|c|c|c|}
\hline Spot & $\begin{array}{l}\text { Accession } \\
\text { number }\end{array}$ & Protein & $\begin{array}{l}\text { Precursor } \\
\text { ion }\end{array}$ & Sequence & E-score & $\begin{array}{l}\text { MS-Blast } \\
\text { score }\end{array}$ \\
\hline & & & 1601.609 & YGQMNEPPGAR & & \\
\hline & & & 2097.371 & LDTGALPSVPVGGATLGR & & \\
\hline & & & 2386.229 & KLNVTCEVQKLLGNNR & & \\
\hline \multirow[t]{2}{*}{428} & & - & 1035.452 & DXXLVYAGR & & \\
\hline & & & 1083.545 & DXXFPCLR & & \\
\hline \multirow[t]{6}{*}{429} & gil78099761 & Arginosuccinate synthase, chloroplast & 1041.424 & YAELVYAGR & $1.2 \mathrm{e}-21$ & 246 \\
\hline & & & 1693.710 & GXXTPGGTLLFNAVR & & \\
\hline & & & 1518.886 & LXXSGVHVVVGTXXR & & \\
\hline & & & 1827.858 & YGFEQPSALKQR & & \\
\hline & & & 2417.218 & KDLSSFESGQLYDQADAAGFLR & & \\
\hline & & & 2074.934 & PEPALELTR & & \\
\hline \multirow[t]{2}{*}{430} & & - & 1271.670 & AXXHTTAAFLR & & \\
\hline & & & 1420.834 & EXXQXXAWALHR & & \\
\hline \multirow[t]{2}{*}{431} & & - & 1334.458 & YQTGLAR & & \\
\hline & & & 1373.536 & VXXDCATANXXGR & & \\
\hline 434 & & - & 1734.700 & FHLTYVNTEFNHGR & & \\
\hline \multirow[t]{2}{*}{436} & gil62510584 & Rab GDP dissociation inhibitor $\beta$ & 922.507 & LYAESLAR & $8.8 \mathrm{e}-13$ & 162 \\
\hline & & - & 2544.244 & FKNSXXLYPLYGLGELPKAFAR & & \\
\hline \multirow[t]{3}{*}{443} & & - & 1177.512 & KLKEEYXXR & & \\
\hline & & & 1236.444 & HNFSSLNDFR & & \\
\hline & & & 1708.669 & GXXQYFTTHTDLVR & & \\
\hline \multirow{5}{*}{444} & gil50400860 & Monodehydroascorbate reductase & 825.446 & NLFYLR & $8.9 \mathrm{e}-28$ & 283 \\
\hline & & & 1080.411 & GYLFPEGAAR & & \\
\hline & & & 1179.473 & QLTAGR & & \\
\hline & & & 1430.145 & LGGGVAAGYAAR & & \\
\hline & & & 1800.535 & SVDEYDYLPFFYSR & & \\
\hline \multirow[t]{4}{*}{451} & gil8928411 & $\beta$-2-tubulin & 1030.578 & SWCDLPPR & $6.7 \mathrm{e}-18$ & 145 \\
\hline & & & 1146.498 & FPXXLNSDLR & & \\
\hline & & & 1274.615 & FKXXLNSDLKR & & \\
\hline & & & 1342.703 & LNVYYNEASGGR & & \\
\hline 453 & gil129699 & Proliferating celll nuclear antigen & 1024.436 & SEGFEHYR & $7.3 e-3$ & 64 \\
\hline \multirow[t]{2}{*}{469} & gil1172586 & Polyphenol oxidase $\mathrm{A} 1$, chloroplastic & 1239.545 & WYLYFYER & $4.0 \mathrm{e}-10$ & 131 \\
\hline & & & 1570.636 & DXXXYAHHSNXXR & & \\
\hline 471 & & - & 1761.840 & YXXDNTLFHLNKLR & & \\
\hline 472 & gil18410026 & Mevalonate diphosphate decarboxylase, putative & 1296.678 & VAYTFDAGNPAVLLAR & $5.1 \mathrm{e}-04$ & 84 \\
\hline \multirow[t]{4}{*}{802} & gil12229922 & Proteasome subunit $\alpha$ type- 6 & 836.352 & NEAAEFR & $5.0 \mathrm{e}-26$ & 261 \\
\hline & & & 1156.455 & HLTLFSPEGR & & \\
\hline & & & 1452.634 & FLXXLATGFTADAR & & \\
\hline & & & 1970.952 & AXXXAELDEHLTALSE & & \\
\hline
\end{tabular}

$\mathrm{X}$ indicates any amino acid.

Supplementary Table 1(b). De novo derived peptide sequences for the identification of proteins from cocoa clone ICS39.

\begin{tabular}{|c|c|c|c|c|c|c|}
\hline Spot & $\begin{array}{l}\text { Accession } \\
\text { number }\end{array}$ & Protein & $\begin{array}{l}\text { Precursor } \\
\text { ion }\end{array}$ & Sequence & E-score & $\begin{array}{l}\text { MS-Blast } \\
\text { score }\end{array}$ \\
\hline i700 & & - & 1151.686 & LVTVEL & & \\
\hline \multirow[t]{2}{*}{ i701 } & & - & 1493.939 & DSENNS & & \\
\hline & & & 1837.012 & ELVEALDSENSLTFR & & \\
\hline \multirow[t]{2}{*}{ i702 } & & - & 905.435 & LHAVYR & & \\
\hline & & & 1451.772 & VFELLQR & & \\
\hline \multirow[t]{5}{*}{ i704 } & gil2499498 & Phosphoglycerate kinase, cytosolic & 981.668 & VLLSSHLGR & $7.9 e-32$ & 331 \\
\hline & & & 1072.694 & YSLAGPLVPR & & \\
\hline & & & 1206.864 & VLLSSHLGKR & & \\
\hline & & & 1807.179 & LVAELPDGGVLLLENVR & & \\
\hline & & & 2075.981 & VDLNVPLDDNFNLTDDTR & & \\
\hline i705 & & - & 860.618 & QSPPYLR & & \\
\hline \multirow[t]{3}{*}{ i706 } & gil224078816 & Anthocyanidin reductase & 980.680 & GYAVNTTVR & $8.5 \mathrm{e}-08$ & 128 \\
\hline & & & 1054.552 & LRLNSR & & \\
\hline & & & 1209.512 & VPTDFGDFRR & & \\
\hline \multirow[t]{3}{*}{ i708 } & gil3913034 & $\beta$-amylase & 1088.505 & KYDWSAYR & $5.8 \mathrm{e}-08$ & 162 \\
\hline & & & 1424.875 & EXXEVAWN & & \\
\hline & & & 1996.900 & SDXXAAELTAGYY & & \\
\hline \multirow[t]{2}{*}{ i709 } & & - & 1233.711 & KXXLEELFAR & & \\
\hline & & & 1950.989 & AHGADAYPFTEER & & \\
\hline \multirow[t]{4}{*}{ i710 } & gil8134568 & 5-methyltetrahydropteroyltriglutamate & 902.527 & WAVHSFR & $1.1 \mathrm{e}-28$ & 291 \\
\hline & & & 1096.645 & YLFAGVVDGR & & \\
\hline & & & 1697.815 & AXXNVLKLDEAALR & & \\
\hline & & & 1658.955 & YQGLGPGVYDLHSPR & & \\
\hline \multirow[t]{6}{*}{ i711 } & gil85700445 & Probable mitochondrial-processing peptidase $\beta$ subunit & 850.451 & KLLTYGR & $2.8 \mathrm{e}-31$ & 282 \\
\hline & & & 900.622 & VWDVLLR & & \\
\hline & & & 986.658 & LTTLPDGLR & & \\
\hline & & & 1284.627 & GQSHFFGYEGR & & \\
\hline & & & 1871.100 & EHLQNYLQTHYTAPR & & \\
\hline & & & 2561.760 & TASQLVANEPATFTGSEVR & & \\
\hline i800 & & - & 989.430 & KDXXHAHR & & \\
\hline
\end{tabular}

\footnotetext{
$\mathrm{X}$ indicates any amino acid.
} 